\title{
Cohort Changes in Social Security Benefits and Pension Wealth
}

Chichun Fang, Charles Brown, and David Weir 


\title{
Cohort Changes in Social Security Benefits and Pension Wealth
}

\author{
Chichun Fang \\ University of Michigan \\ Charles Brown \\ University of Michigan \\ David Weir \\ University of Michigan \\ September 2016 \\ Michigan Retirement Research Center \\ University of Michigan \\ P.O. Box 1248 \\ Ann Arbor, MI 48104 \\ www.mrrc.isr.umich.edu \\ (734) 615-0422
}

\section{Acknowledgements}

The research reported herein was performed pursuant to a grant from the U.S. Social Security Administration (SSA) funded as part of the Retirement Research Consortium through the University of Michigan Retirement Research Center Award RRC08098401. The opinions and conclusions expressed are solely those of the author(s) and do not represent the opinions or policy of SSA or any agency of the federal government. Neither the United States government nor any agency thereof, nor any of their employees, makes any warranty, express or implied, or assumes any legal liability or responsibility for the accuracy, completeness, or usefulness of the contents of this report. Reference herein to any specific commercial product, process or service by trade name, trademark, manufacturer, or otherwise does not necessarily constitute or imply endorsement, recommendation or favoring by the United States government or any agency thereof.

\section{Regents of the University of Michigan}

Michael J. Behm, Grand Blanc; Mark J. Bernstein, Ann Arbor; Laurence B. Deitch, Bloomfield Hills; Shauna Ryder Diggs, Grosse Pointe; Denise Ilitch, Bingham Farms; Andrea Fischer Newman, Ann Arbor; Andrew C. Richner, Grosse Pointe Park; Katherine E. White, Ann Arbor; Mark S. Schlissel, ex officio 


\title{
Cohort Changes in Social Security Benefits and Pension Wealth
}

\begin{abstract}
We utilize three sets of data resources - the Health and Retirement Study (HRS), linked Social Security earnings records of the HRS respondents, and publicly available pension plan descriptions - to study pension wealth accumulations among the recent HRS cohorts. We document the trends in pension wealth over time and across cohorts during a period in which the economic consequences of the Great Recession were significant. However, given that pension wealth of many respondents were imputed in earlier waves due to the lack of information about pension plan provisions, there is the question of how much of the changes in pension wealth should be attributed to errors in imputation. The recently available pension plan descriptions from private employers’ Form 5500 filings and public employers' websites, which improve the respondent-plan linkage over what was available in previous waves, allow us to examine this exact question. In particular, we show that the newly available sets of information not only reduce the need for imputation, but also enable us to identify the plans not reported by HRS respondents in the survey and the retirement wealth associated with these plans. Finally, we also test the validity of the earnings projection methods used to produce Social Security and pension wealth estimates in the HRS, and we end our report with a discussion over the pros and cons among the projection methods.
\end{abstract}

\section{Citation}

Fang, Chichun, Charles Brown, and David Weir. 2016. "Cohort Changes in Social Security Benefits and Pension Wealth.” Ann Arbor, MI. University of Michigan Retirement Research Center (MRRC) Working Paper, WP 2016-350.

http://www.mrrc.isr.umich.edu/publications/papers/pdf/wp350.pdf

\section{Authors' acknowledgements}

The authors thank Amy Butchart and Yanling Xu for excellent research assistance. 
The Health and Retirement Study (HRS) creates the potential to follow changes in retirement preparation at midlife (ages 51-56) through the introduction of new cohorts every six years. The cohort added in 2010 also included an expansion of the minority sample of HRS, with financial support from the Social Security Administration (SSA). This new 2010 cohort coincides with the recent availability of private-sector pension plan descriptions provided online by the Department of Labor Form 5500 filings, substantially improving our ability to link respondents and the detailed features of their pension plans. Additionally, linked Social Security data have also recently become available for the 2010 cohort. We use these new data sources, in conjunction with HRS survey data, to measure pension and Social Security wealth, and to conduct sensitivity analyses of cohort changes and racial disparities to key assumptions used in their construction.

We consider the implications of assumptions used in the construction of pension and Social Security wealth in the context of cohort change. The primary estimates (weighted) are shown in Table I for individuals ages 51-56 at six-year intervals, corresponding to the entry of new cohorts into HRS. Most readers will think "household wealth" is what we call "total wealth." Total wealth increased from 1992 to 2004 then dropped sharply in 2010 for the cohort having experienced the Great Recession. Despite financial losses, in 2010 for the first time, DC wealth exceeded DB wealth, reflecting the long-term trend away from DB plans in the private sector. Social Security wealth rose somewhat after 1998, due mainly to the increasing real value of the maximum taxable earnings and increasing labor force participation among women. The real value of annuitized retirement wealth (Social Security plus DB) fell from 1998 to 2004 and again to 2010. The real value of nonannuitized, tax-advantaged retirement wealth (DC plus IRA) rose steadily, but not fast enough to offset the decline in annuitized wealth. The newly available plan 
document information from the Form 5500 database allowed us to obtain pension plan data for a much larger fraction of private-sector employers. Along with the linked W-2 earnings data, we were able to estimate the retirement wealth not reported in the survey. Accounting for wealth in the plans that the HRS respondents failed to report increased retirement wealth by about $10 \%$.

The decision to code all the matched DB plans found from the Form 5500 database was justified by the variation in plan generosity. We show that, holding individual and job characteristics constant, there is substantial variation in plan wealth across and within sectors. Public sector plans tend to yield larger wealth ${ }^{1}$; among private sector plans, frozen plans and those taken over by PBGC had lower level of benefits compared to the others. Hence, the newly available plan documents improved the quality of data in three dimensions: They reduced the need for imputation, they captured and preserved the variation in plan generosity, and they allowed us to identify wealth in plans not reported by HRS survey respondents.

We explain each component of data used to perform our analysis in Sections I through IV. In Section V, we consider these trends at ages 51-56 across the distribution of lifetime income and for different racial/ethnic groups. We start with the mean trend in retirement wealth over time by gender and ethnic groups. We then use a variance decomposition model to assess the cohort changes across the wealth distribution. In Section VI, we examine the validity of earnings projection used to estimate retirement wealth by comparing the earnings projection for 2010 used in 2004 and actual earnings data in 2010. We also discuss how the errors in earnings projection affect our estimates of retirement wealth, as well as the pros and cons among various methods of earnings projection. Section VII concludes.

\footnotetext{
${ }^{1}$ Contributions into public pension plans were not used in the comparison of public versus private sector plans.
} 


\section{PENSION WEALTH IN DEFINED BENEFIT PLANS}

Estimating the annual pension to be received from a defined benefit plan requires knowledge of the detailed provisions of the plan (e.g., the benefit formula) and the features of the worker’s employment history (e.g., years of service and final salary) on which the benefit depends. Pension wealth is then the discounted value of these annual benefits. HRS calculation of respondents' DB pension wealth relies on external information about plan provisions and survey information about employment history. In this section, we describe the procedures we followed to assemble this information (or to impute it when it was not available) and then to use it to calculate present values of pension wealth for various assumed retirement dates.

\section{A. Obtaining and Coding Plan Descriptions}

Identifying Employers. The search for provisions of HRS respondents' DB pension plans began with the respondent's survey report of employer name, address, and phone number. Each report was individually reviewed, and web searches and consultation of the business directory ReferenceUSA were used to determine accurate local and parent employer information. Multiple criteria were assessed including employer name, location, industry, and phone. In addition, a fuzzy match algorithm (Wasi and Flaaen, 2015) was used to compare self-reports in the survey to employer information in an internal database of past survey reports of employers as well as previous Form 5500 filings. Employer identity matches were found for 3,807 of the 3,930 HRS respondents in 2010 who reported participating in a pension at their current employer and who were not self-employed.

Finding Employer Plan Descriptions. Most public sector plans have descriptions available online, though local variations within state-sponsored plans (e.g., teachers) require adjudication. In previous waves, HRS has attempted to obtain private sector plan descriptions 
directly from employers (without identifying study participants), and indirectly by asking participants to obtain the information from their employer. Success rates from both approaches have been low. Beginning in 2008, the Department of Labor began posting detailed Form 5500 filings. ${ }^{2}$ Form 5500 is an annual filing mandated by the Employee Retirement Income Security Act (ERISA) to monitor the financial health of plans and is required of employers with more than 100 participants in a tax-advantaged retirement plan. ${ }^{3}$ Descriptions of eligibility, vesting, and benefit accrual rules are usually attached to the Form 5500 filing. Public sector plans are not covered by ERISA; hence, they do not have corresponding Form 5500 filings.

Retirement plans in the Form 5500 database can be uniquely identified by the sponsor EIN and plan number. HRS had hoped to use EINs obtained in linked Social Security administrative records to facilitate this linkage. However, the most recent linked records do not have actual EINs, only a scrambled version. EINs publicly available on websites like ReferenceUSA were used, but the primary method of finding employers in Form 5500 databases was through name and address. Once the employer was located in DoL's Form 5500 database, we reviewed all the plans sponsored by that employer to identify those plans for which the corresponding HRS respondent appeared to be eligible. We followed the similar procedure to determine the eligibility of respondents working in the public sector, using the plan descriptions we downloaded from their websites.

Plan Types and Plan Coding. We call a defined-benefit plan document "codable" if it contains sufficient information to determine whether a respondent is eligible for this plan, when

\footnotetext{
${ }^{2}$ A web-based interface of this database is located at https://www.efast.dol.gov/portal/app/disseminate.

${ }^{3}$ While only $12 \%$ of all private-sector plans have more than 100 participants, these plans accounted for 98\% (85\%) of all active participants in DB (DC) plans in 2010. See U.S. Department of Labor, Employee Benefit Security Administration (2012), Tables A1 and A1(a).
} 
the benefit will vest, and how the benefit is calculated upon retirement or separation. After we found a codable plan document for a certain respondent, the plan was coded using a sophisticated coding tool that captures formulas and parameters for use in calculating benefits (Fang et al., 2016). Information in the documents that we found may not be consistent with the respondent's self-report, and sometimes we were not able to find enough information to establish the respondent-plan link. In these cases we assigned plan parameters by imputation.

Due to resource constraints, we did not attempt to code DC plans. Respondent self-reports of DC account balance were used in preference to a calculated balance, and imputed as needed (see Section II). Cash balance plans are considered as DB plans under ERISA and in most cases required coding in order to calculate benefits (balance). In our analysis, we also considered wealth in cash balance plans as DB wealth.

Imputation of DB Plan Coding. A respondent who reported being covered by a DB plan but for whom we could not identify a DB plan for which s/he was eligible became a "seeker"the respondent needed a set of plan parameters from which benefits could be calculated. For each "seeker," we assigned a plan from the "donor" pool of coded plans as this respondent's imputed DB plan. Table II shows the composition of donor and seeker pools based on both survey response and the plans for which the respondent might be eligible.

More specifically, we put all the respondents into bins constructed based on a hierarchy of sector (two categories: public versus private), union status (two categories: covered by a collected bargaining contract or not), education (five categories: less than high school, GED, high school, some college, and college or above), industry (19 categories), occupation (25 categories), size of the parent company (four categories: less than 25, 25 to 99, 100 to 499, and 
500 or more), and tenure in the current job (6 categories: less than five years, five to 10 years, 10 to 15 years, 15 to 20 years, 20 to 25 years, and 25 years and above).

For the bins that had at least 5 respondents and at least one donor, each seeker in these bins took a random draw (with replacement) of donors in the same bin. The drawn donor plan hence became the seeker's "imputed" plan. Bins that had less than five respondents or no donors were aggregated "upward" in the hierarchy until they had at least five respondents and a donor, and seekers in these bins were then assigned donor plans in the same manner. ${ }^{4}$

\section{B. Respondent Information Needed to Calculate Benefits}

Years of service and earnings are two of the most important factors that determine the level of benefit upon retirement in a DB plan. Below we briefly explain how these measures were constructed for each respondent.

Hire Date and Years of Service. A participant's hire date is important for determining plan eligibility and measuring years of service credit. HRS respondents were asked about the date of hire at their current employer when the job/employer was reported for the first time in the survey. HRS usually skips the date of hire question in later waves when the respondent reports working for the same employer and only re-asks the question every two or three waves for confirmation purposes. When multiple measures of hire date were available, they can be inconsistent. In this work, inconsistent reports of hire date were compared to Social Security earnings records when they were available. When earnings records could not be used to resolve

\footnotetext{
${ }^{4}$ This rule was developed to avoid small bins.
} 
inconsistent reports, the earliest reported hire date was used to determine plan eligibility, while service credit was calculated from the latest reported hire date. ${ }^{5}$

Earnings. The Pension Estimation Program projected earnings forward from the interview year based on salary at time of interview and an assumed rate of earnings growth from the interview year. To establish earnings on the pension-covered job we began with HRS employment section self-report data on weeks worked per year, hours worked per week, and hourly wage. Missing data on weeks and hours were imputed based on adjacent waves. If the hourly wage was missing, a series of rules were used to select and apply substitute measures of income. $^{6}$

Whenever the information from a different wave/year was used to fill in as the earnings in 2010, we adjusted these earnings to 2010 U.S. dollars using the following rule:

- For the 2008 earnings, we applied a 4\% increase for government sector and a 2.5\% increase for private sector;

- For 2012 wage, we applied a 3\% decrease for government sector and a 4\% decrease for private sector.

The motivation behind these rules, rather than using the wage growth rate assumed in the Annual Report of the Board of Trustees of the OASDI Trust Funds, was that we wanted to

\footnotetext{
${ }^{5}$ Multiple hire dates could be the result of multiple spells with the same employer. We surveyed the jobs/plans in which our respondents experienced multiple job spells. Many plans did not specify the rules to determine eligibility and years of service for participants who had multiple spells with the same employer. Among those that we could tell, however, using the earliest date for eligibility and the latest for service credit seemed to be a valid assumption.

${ }^{6}$ If the respondent was paid by salary, we used the annual salary reported in the HRS employment section. If the respondent was paid piece-work or "other," we used annual income in the prior calendar year as reported in the income section, provided the prior year job was the same as the current one. If this information was not available, income was calculated from adjusted employment section measures of income in adjacent interview waves for respondents with the same job in the relevant wave. Failing that, the current interview wave's income section data regarding the past year's income were used if the reported hire date was before 2009. If none of these measures were available, income was imputed to be the median income of respondents paid in that method (salary, hourly, or "other”).
} 
account for the earnings growth at the individual level. Since people tend to leave near their peak earnings and are replaced in the labor force by people at lower earnings on their life-cycle trajectories, the in-sample wage growth (which is the earnings growth at the individual level) is more appropriate than the SSA wage index or the long-term earnings growth rate assumed in the OASDI actuarial report (both are earnings growth of the whole population) for our purpose. ${ }^{7}$ We obtained the in-sample wage growth using the average earnings changes among the HRS respondents who stayed in the same jobs and had no missing earnings information between 2008 and 2012. The growth rates were calculated by sector to reflect different earnings trajectories between public and private sectors during and after the Great Recession.

\section{Calculation of DB Benefits}

Pension Estimation Program. The Pension Estimation Program was used to calculate future benefits based on the coded plan parameters and formulas and the self-reported respondent characteristics (Fang, et al., 2016). Benefit calculations were made for all DB plans for which the HRS 2010 respondent was eligible, regardless of self-report. The current public release version of 2010 DB wealth is consistent with prior releases in that it only reports DB wealth for respondents who self-reported having a DB plan. That calculation was made from the imputed DB plan if no matching plan was found at the respondent's employer.

Present Value (PV) Calculation. The present value of benefit wealth from a DB plan was calculated as:

\footnotetext{
${ }^{7}$ The Pension Estimation Program had two options for earnings. It either took earnings at the baseline year for everybody and assumed the same earnings growth rate across individuals and over time; or it took the full earnings history (from the date of hire to retirement) for everybody. It did not, for example, allow in-sample earnings growth that differed across individuals. We discuss the validity of earnings projections in Section VI.
} 


$$
P V\left(T_{0}\right)=\sum_{t=T_{0}}^{119}{ }_{t} P_{T_{0}} *\left[\frac{1+C O L A}{1+r}\right]^{t-T_{0}} * B\left(T_{0}, t\right)
$$

where: ${ }_{t} P_{T_{0}}$ is the probability of surviving for $t$ years after retiring at age $T_{0}$, conditional on being alive at $T_{0}$ (computed using sex- and birth cohort-specific mortality tables ${ }^{8}$ ), COLA is the plan-specific or user-provided annual growth rate of nominal payment (for most plans COLA=0), $r$ is the nominal interest rate (5.7\%), and $B\left(T_{0}, t\right)$ is pension benefit in year $t$ after the quit date.

DB wealth estimates were calculated or imputed for each respondent at various “milestone" retirement ages $\left(T_{0}\right)$. The calculations assumed a real interest rate of $2.9 \%$ and an inflation rate of $2.8 \%$ according to the intermediate economic assumption in the 2010 version of the Annual Report of the Board of Trustees of the OASDI Trust Funds. To facilitate the comparison, the present values were then discounted or inflated to 2010 U.S. dollars. Values Corresponding to Different Possible Dates of Retirement. Present values of pension wealth were calculated or imputed at eight different retirement (separation) ages: 60, 62, 65, 70, the plan's stated early retirement age, the plan's stated normal retirement age, the respondent's own expected retirement age, and as of the end of 2010.

At any given age, the Pension Estimation Program has three sets of wealth PVs: PV of early retirement benefits per plan language, PV of normal retirement benefits per plan language, and PV of benefits that are already vested (i.e., "vested and deferred"). In a given specific ageyear, the PVs at early/normal retirement age would be zero for the years when the respondent was not yet eligible for early/normal benefits. Similarly, the PV of vested and deferred benefits would be zero if the benefits were not vested yet. In our calculation, we defined the maximum

\footnotetext{
${ }^{8}$ We used the cohort mortality table as of 2010 provided by the SSA.
} 
among these three numbers at a given age as the wealth at that age; i.e., we assumed that respondents would choose the provision that yielded the largest benefit payments.

The DB pension wealth estimate at age 60 is the present value of all future cash flows that the respondent will receive if she or he retires on the $60^{\text {th }}$ birthday. For respondents who are younger than 60 in 2010, this definition is straightforward. For the respondents older than 60, however, the wealth at age 60 is defined as the present value of all the future cash flows from 2010 onward assuming that the respondent has retired at age 60. In other words, we excluded all the benefits that had been paid in our calculation. Pension wealth at age 60 would be missing if the respondent was older than 60 when the current job started, and it would be zero if the benefits were not vested yet at age 60 . We defined and calculated the wealth estimates at ages 62,65 , and 70 similarly.

Pension wealth at the early retirement age is the benefit wealth when a respondent initially becomes eligible for early retirement benefit. Empirically, in a Pension Estimation Program output that chronologically lists the benefits at each retirement/quit age, this would be the first age when the PV at early retirement age becomes non-zero. We also provided the corresponding age in the public release of the pension wealth estimates file. Note that the early retirement age is defined at the person-plan level. It could differ across respondents in the same plan if, for example, the retirement age eligibility is determined by a combination of age and years of service. We defined and calculated the PV at normal retirement age in a similar manner.

PV at the expected retirement age is the pension wealth at the expected retirement age reported by the respondent in the 2010 HRS interview. In the survey, such dates were reported at the pension plan level. We aggregated the measure to job level by picking the first retirement date reported in the plans associated with that specific job. If the self-reported expected 
retirement age was missing (including “don’t know” and “refuse”), we imputed it using the nearest neighbor matching. If the imputed expected retirement age was smaller than the respondent's age in 2010, we assumed that the respondent expected to retire at the end of 2010. In other words, we assumed expected retirement age to be greater than or equal to the current age as of 2010. For respondents who were younger than 80 as of 2010, we also capped (top-coded) the expected retirement age at 80 . For the respondents who were older than 80 as of 2010, we assumed they expected to retire in the end of 2010. Note that, if the benefits were not vested as of the expected retirement age, the PV at expected retirement age would be zero. We also provided the expected retirement age (modified, if necessary, according to the above rules) as well as an indicator of whether the expected retirement age was imputed in the pension wealth estimates file.

Finally, following Gustman, Steinmeier, and Tabatabai (Gustman et al., 2010a; b), we define PV in the end of 2010 as a proration of wealth PV at the expected retirement age based on the ratio of the respondent's years of service as of 2010 to the respondent's years of service at the expected retirement age. Hence, it is the linearly-approximated portion of benefits at expected retirement date that the respondent has earned based on years of service as of 2010. It is, therefore, not exactly equal to the benefits someone would receive if s/he stopped work at the end of 2010: In some cases the PV might be zero if the respondent quit working in 2010 because vesting had not yet occurred; and in many cases, DB benefit accrual is greatest at the end of career (just the opposite of progressive Social Security benefits).

The other limitation of the GST approach to prorating benefits is the reliance on expected age at retirement. The expected retirement age given by a young respondent may not be wellconsidered in light of the financial incentives of the plan. Indeed, in some cases, this wealth is 
considerably less than wealth at 62 or 65 . In this paper, we constructed prorated DB wealth based on the full spectrum of possible retirement ages. For each estimate in the public file (age 62, age 65, normal retirement age, and expected retirement age), we calculate linearly prorated wealth at age in 2010. We take the second-highest prorated value among these estimates.

\section{Variations in Plan Generosity and Importance of Imputation}

A justification for actually coding all these DB plans (rather than just using a “generic” plan) is the variation in plan generosity. Are the variations in DB plan wealth across respondents driven by the variations in generosity of their plans, or do they simply reflect the variations in their earnings and years of service? In the extreme scenario where all the DB plans have similar provisions, identifying and coding the plans that HRS respondents are eligible for does not add much value to the understanding of pension wealth and retirement preparation.

To isolate the effects of individual characteristics (namely earnings and seniority) versus plan generosity on plan wealth, we fed a stylized earnings profile into all the plans coded in 2010. This “typical” HRS respondent was a man born in 1954, started the current job in 1989, earned \$48,600 as of 2010 (the median earnings among the HRS respondent who were working as of 2010), and quit working at age 65. We then calculated the wealth of this stylized respondent under each plan. The result is shown in Figure I.

It is clear from Figure I that, holding earnings and seniority constant, there is substantial variation in plan wealth. Public sector plans tend to yield higher wealth than private sector plans. $^{9}$ The difference at the mean is about $\$ 150,000$. Additionally, many private sector plans

\footnotetext{
${ }^{9}$ This does not necessarily mean public employees get "better deals" in their pension plans. Many of the public sector plans are contributory, so public employees may have already paid into these plans. Also, since many public employees are exempted from Social Security, a higher level wealth in a public DB plan per se does not necessarily indicate better retirement preparation.
} 
have been frozen or transformed into cash balance plans. As Figure II shows, frozen plans (including the plans that have stopped accruing benefits or have become cash balance plans) overall yield less wealth than nonfrozen plans in the private sector. About $30 \%$ of the private sector HRS respondents whose plans were coded in 2010 have frozen plans, and frozen plans on average yield \$50,000 less than nonfrozen plans in the private sector under our stylized earnings profile. Hence, Figures I and II suggest that, in order to assess the retirement preparation, it is important to match HRS respondents to the correct plans that they have.

\section{PENSION WEALTH IN DEFINED CONTRIBUTION PLANS}

To be consistent with earlier waves of pension wealth estimates, we constructed pension wealth in defined contribution (DC) plans where respondents reported having such plans, relying on self-reported account balances from the current job as of the 2010 survey. A respondent could report multiple accounts balances from the same job. ${ }^{10}$ The total DC wealth was computed as a sum of all accounts from current job in 2010. If some of these amounts were missing, they were imputed.

Imputation of Account Balance in DC Plans. When the account balance was not reported, we imputed the respondent's DC account balance using a variation of the nearest neighbor matching method. The HRS uses unfolding brackets to obtain information on dollar values for which the respondent does not report an actual value. We first aggregated the account balance up to the respondent level for those who had more than one DC account, accounting for both actual and bracketed answers. For example, if a respondent reported $\$ 100 \mathrm{~K}$ and $\$ 25 \mathrm{~K}$ in each account, her total balance was $\$ 125 \mathrm{~K}$. If a respondent reported a balance of $\$ 120 \mathrm{~K}$ in the first

\footnotetext{
${ }^{10}$ In plans that have both DB and DC features, the term "DC account balance" pertains to the balance in DC component of such plan.
} 
account and "between $\$ 20 \mathrm{~K}$ and $\$ 50 \mathrm{~K}$ ” in the second, she was considered to have a bracketed answer between $\$ 140 \mathrm{~K}$ and $\$ 170 \mathrm{~K}$. If the report was “between $\$ 20 \mathrm{~K}$ and $\$ 50 \mathrm{~K}$ ” in the first account and "between $\$ 0$ and $\$ 20 \mathrm{~K}$ " in the other, the balance was between $\$ 20 \mathrm{~K}$ and $\$ 70 \mathrm{~K}$. If the reports were "between $\$ 20 \mathrm{~K}$ and $\$ 50 \mathrm{~K}$ ” and “DK," the combined balance was "more than \$20K.”

We identified “nearest neighbors” by assigning predicted values of DC balance. Prediction equations were estimated on those respondents who reported cardinal values for all DC plans. Different prediction equations were estimated for each gender. We regressed the logarithm of respondent's DC account balance in 2010 on: respondent's age, three marital status indicators (married, divorced, or widowed), eight region of residence dummy variables, two dummy variables for minority (non-Hispanic black or Hispanic), three education categories, nativity, years of work experience, a union status indicator, a dummy variable indicating whether respondent also has a DB plan, a health insurance indicator, a home ownership indicator, logarithm of annual wage for the current job, logarithm of total household income, and occupation and industry indicators for the current job. For the logarithm of account balance, wage, and income variables, we used the inverse hyperbolic sine transformation, $\ln \left(\sqrt{y^{2}+1}+\right.$ $y$ ), rather than $\ln (y)$, so the observations with zero account balance, earnings, or income were not dropped. Based on the coefficients from this regression, we calculated a "predicted” account balance for all respondents, including those whose answers were actual numbers, bracket numbers, or missing. The sample was then sorted by this predicted account balance.

In the next step, a “nearest neighbor” was found for each respondent whose reported DC account balance was in brackets or missing. The actual account balance of the nearest neighbor was assigned as the imputed account balance for a respondent whose report was in brackets or 
missing. For a respondent whose reported DC account balance was missing, finding a nearest neighbor is straightforward. It was simply the respondent who reported an actual number in the account balance and had a predicted account balance adjacent to that of the respondent who needed an imputed balance. For a respondent whose report balance was in brackets, it was the most adjacent respondent whose actual account balance fell in the same reported bracket of the respondent who required imputation. That is, the "nearest neighbor" of a respondent who had a reported balance of "between $\$ 20 \mathrm{~K}$ and $\$ 50 \mathrm{~K}$ ” was the respondent with the most adjacent predicted balance among those who had an actual balance between $\$ 20 \mathrm{~K}$ and $\$ 50 \mathrm{~K} .{ }^{11}$ In this way, the information in bracketed answers was preserved in the imputation process.

\section{COMPARING RESPONDENT REPORTS AND EMPLOYER}

\section{MATCH INFORMATION}

The 2010 HRS public release of current job pension wealth estimates are based on methods developed by GST for 1992-2004. In particular, because of the rather unsuccessful efforts to match respondents to private employer pension plans, those methods rely on respondent reports of pension coverage and plan type. If no employer match was obtained, or no matching plan found for that employer, the value of the plan was imputed.

Table III demonstrates the value of the Department of Labor's posting of Form 5500 records. In both 2004 and 2010, the HRS was able to match most public-sector workers to their plan information because public employers post their own plan information online. In 2004, only about one in three private sector pension-covered workers was successfully matched

\footnotetext{
${ }^{11}$ For example, respondent A reported a DC balance “between $\$ 20 \mathrm{~K}$ and $\$ 50 \mathrm{~K}$.” The respondent who had the closest predicted balance reported DC balance $\$ 10 \mathrm{~K}$, and the respondent who had the second closest predicted balance had a reported balance of $\$ 35 \mathrm{~K}$. This $\$ 35 \mathrm{~K}$ respondent is considered as the “nearest neighbor” for the purpose of this imputation, and the imputed DC balance for respondent $A$ is $\$ 35 \mathrm{~K}$.
} 
through requests made of employers. In 2010, more than 90\% were matched through the DoL website.

The higher matched rate likely also improved data quality by reducing the need for imputation. Table IV splits respondents into two groups: those whose plans were matched and coded both in 2004 and 2010, and those whose plans were matched and coded in 2010 but not in 2004 (so their pension wealth estimates in 2004 were imputed). The former group is further split by sector. To eliminate the variations in other factors that affect DB wealth (for example, respondents who stayed in the same job between 2004 and 2010 would have gained six years of seniority) other than plan provisions, the first two rows in Table IV were calculated by feeding the same 2004 job and individual characteristics into 2004 coded plans (the first column) and into 2010 coded plans as if they were coded in 2004 (the second column). If there were no change in coded plan provisions, numbers in these two columns would be identical. Hence, the change in wealth in the first two rows reflects changing plan provisions, as private plans change more often than public plans. The largest mean absolute difference in the last row is expected. Since respondents in the last row had their wealth imputed in 2004, any noise in the wealth estimates due to imputation would show up in the mean absolute difference. Assuming that plans in the second and third rows were otherwise similar, imputation on average added $\$ 40,000$ of error $(\$ 131,308-\$ 90,064)$ into plan wealth in 2004 for each respondent. The high match rate in 2010 alleviates this issue by reducing the need for imputation.

The very high rate of employer matching also allowed us for the first time to compare systematically the wealth in plan types reported by respondents with the wealth in plan types offered by employers for which that respondent is eligible. Table V shows the estimates of 2010 pension wealth, in total amount reported by all HRS respondents age 51-56 in 2010 in the survey, 
according to whether we relied on respondent reports of plan type, as was done in the public versions of HRS pension wealth back to 1992, or instead relied on plans offered by employers to which the respondent can be matched. Imputations were used to estimate DB wealth when a respondent reported DB but no DB was matched, and when a respondent did not report a DC but was matched to one. It is comforting that half or more of total pension wealth of all types was in plans for which the respondent and employer match agreed on the plan type. Pure plan switches, where the respondent said DB and the employer only offered DC (or vice versa), accounted for a very small part of the total wealth, and the totals were not very different whether we rely on respondents or employers. Cases in which the respondent reported both types of plans but can only be matched to one or the other account for a slightly higher share of pension wealth, and the net change from replacing the respondent's report with employer data was to reduce wealth by about $\$ 30$ million out of nearly $\$ 600$ million total, or about 5\%. A larger impact is seen in cases where a respondent reported only one type of plan but was found to be eligible for both. If we were to add all the plans for which the respondent appears to be eligible (but did not herself report) it would add about $\$ 100$ million in pension wealth in 2010 , or about $15 \%$. Slightly more of this came from DC plans than from DB plans. Adding DC wealth in all cases where the respondent was eligible for a plan but did not report participating in it is almost surely an overadjustment, as respondents might choose not to contribute to plans that required a worker contribution as a condition for participation.

Determining which estimate of pension wealth is closest to the truth would require accurate data on the plan type(s) of each HRS respondent. Such data are not available. However, the $\mathrm{W}-2$ records contained in the linked HRS-SSA administrative records, which list the amount of tax-deferred contribution into qualified defined contribution plans (see Dushi and Honig, 2015 
for a detailed discussion), ${ }^{12}$ are helpful in some cases. The presence of tax-deferred contribution in the W-2 is good evidence of current contribution (participation) in a DC plan. The converse is not true. That is, someone who is not currently contributing may nevertheless have wealth in a DC plan at their current employer. Linked SSA administrative records also provide no information on whether an individual participates in a DB plan. Another limitation of administrative records is that they are only available for respondents who provided consent. About half of all workers in HRS 2010 had provided consent as of the most recent linkage. The W-2 evidence tends to support the employer match estimates for DC wealth. Those estimates added about $\$ 57$ million in DC wealth to respondent reports (see Table V). Imputing values to plans implied by the $\mathrm{W}-2$ deferred compensation field and adjusting the total for the rate of Social Security consent would add about $\$ 60$ million to respondent reports. While the employer match and W-2 link seem to agree well in terms of overall "missing” DC wealth at about $10 \%$ or less, they do not necessarily agree well at an individual level.

Table VI shows the percent of cases with deferred compensation in their $2010 \mathrm{~W}-2$, among those with linked administrative records. It reaches only as high as $75 \%$ among cases where respondents report DC plans and we match them to DC plans for their employer, so in all likelihood 25\% of DC plans are missed by the linked W-2 data alone. ${ }^{13}$ When respondents and employers agreed that the only plan is a DB plan, the administrative data finds deferred compensation nearly $12 \%$ of the time. The total value of such plans is $\$ 1.6$ million (based on our

\footnotetext{
${ }^{12}$ We only include contributions into 401(K) and 403(B) plans for the purpose of this paper.

${ }^{13}$ More DC plans are missed in the public sector than in the private sector, likely due to how state-level plans are treated for tax purposes. Public employees who are not covered by Social Security pay mandatory contributions into their state pension plans, which are categorized as 401(a) for tax purposes regardless whether DC options are available or not. Neither employer nor employee contributions into 401(a) plans are reported in W-2. As a result, participation into DC options under such state-level plans will not show up in W-2 even if employee contributions are required.
} 
imputations for DC plans not reported by respondents). If we inflate on the assumption that the people without linked administrative data had the same rate, that would come to \$3.2 million. Among cases that reported a DC but could only be matched to a DB, $62 \%$ had deferred compensation in their $\mathrm{W}-2$ record, and this would come to $\$ 10.5$ million if fully imputed. Finally, the W-2 records indicate deferred compensation for some people who reported no participation at all. This comes to $\$ 13$ million in total value. So if we were to take all the cases of W-2 deferred compensation as valid DC plans and impute values to them and to the similar respondents without administrative linkage, we would add about \$27 million more to the total value of DC plans, about a 4\% increase over what the survey estimates.

\section{MEASURES BASED ON LINKED SOCIAL SECURITY ADMINISTRATIVE DATA}

\section{A. Social Security Wealth at Ages 51-56}

The public versions of the HRS Social Security wealth data are described in Fang and Kapinos (2016). The public measures were calculated for persons with linked data, and imputed for others. We made several modifications for the goals of this paper. First, sample restrictions imposed by SSA limit the public versions to persons who had not yet claimed SS benefits by the survey date. That has the potential to significantly distort analyses of cohort change, because the fraction of 51-56 year olds on SSDI has doubled from 1992 to 2010, from 4\% to 8\%. In this report we imputed SS wealth for those not included in the public SS wealth files. In the future we intend to calculate it directly from SS records for those who are linked, and make those estimates of Social Security wealth available.

The second modification was to adjust the SS wealth estimates to remove the wealth due to projected future earnings, so the SS wealth only reflects the earnings history upon the 
respondents' entry into the HRS in order to facilitate the comparison at baseline years across cohorts. We began by calculating wealth without projected earnings for those in the linked sample. We then calculated pro-rating shares for each individual as the ratio of wealth based only on past earnings to wealth assuming work to age 62, using an income projection method based on last five years of earnings from the W-2 (see Fang and Kapinos, 2016). These shares were then imputed for the full sample, and adjusted wealth is calculated for everyone. We only include the benefits based on the respondent's own earnings history and exclude spousal and survival benefits.

\section{B. Lifetime Earnings at Ages 51-56}

In order to evaluate retirement savings, and to permit analysis across the income distribution, we constructed measures of true lifetime earnings using detailed earnings in the linked administrative records. The linked administrative data for covered earnings begin in 1951, but detailed earnings, which include earnings from jobs not covered by Social Security, and earnings above the cap on FICA-taxable earnings, begin in 1978. They thus represent a different part of the life cycle for different cohorts. For the cohort 51-56 in 1992, the detailed earnings file covered earnings from about age 40. For the cohort 51-56 in 2010, it covered earnings from about age 22. We imputed earnings not subject to FICA tax prior to 1978 based on that individual's ratio of detailed earnings to covered earnings in 1978-91, and other characteristics. ${ }^{14}$

\footnotetext{
${ }^{14}$ Given the relatively low level of FICA taxable earnings cap in earlier years, it was not uncommon to have covered earnings top-coded before 1978. Among the person-year records that had non-zero earnings in our data, $19 \%$ were top-coded in 1951. That number slowly increased to $34 \%$ in 1971 and gradually declined to $20 \%$ in 1977 . Kopczuk, Saez, and Song (2010) used quarterly earnings data and found that less than $1 \%$ of the workers reached the FICA cap in the first quarter of the year. For this small group of workers, they imputed the earnings in the first quarter assuming earnings followed a Pareto distribution and multiplied it by four as the total yearly earning. For the rest of person-year records that were top-coded, they imputed the total yearly earnings as four times the largest quarterly earnings before the cap was hit within a person-year. We were not able to adopt their strategy because our records were at the yearly level. We hence used the ratio between covered and total earnings after 1978 and assumed the
} 
We also discovered some problems with the linked data, in that detailed earnings are not available for all linked persons in all years, and in some cases detailed earnings are below covered earnings. We, therefore, used covered earnings in place of detailed earnings when covered earnings exceeded detailed earnings.

A second challenge to using administrative earnings data for this purpose was that different respondents signed consents at different dates and these different consents require that linkage end at different dates. Because some cohort members entered the study (and consented to linkage) as younger spouses prior to the year in which their birth cohort became age-eligible, we do not always have complete earnings data up to the year of age-eligibility. Everyone in the linked data has data to at least 1991. For people with any linked data, we imputed earnings in the years between the end of linked data and their cohort's year of entry into HRS in three pieces, 1992-97, 1998-2003, and 2004-2009. For each six-year period we constructed estimates of earnings reported in HRS. We sorted the sample by birth cohort and whether or not there were positive earnings in HRS. We then estimated regression models for linked earnings separately for each group in each interval using HRS earnings, W-2 earnings from 1978 to the beginning of the interval, age, education, and gender as predictors. R-squared was generally between 0.5 and 0.6. We then predicted values for everyone who remained in HRS over that interval. We sorted on predicted earnings within cohorts and whether or not there were positive earnings in HRS and used nearest-neighbor imputation.

Finally, we imputed a lifetime earnings value for everyone in our cohorts of interest, but not in the linked administrative data, again using nearest neighbor. The previously imputed 
estimates of Social Security wealth were used in this imputation to ensure some consistency between the two.

\section{COHORT CHANGES IN LIFETIME EARNINGS AND RETIREMENT WEALTH}

\section{A. Trends at the Mean}

Figure III shows the cohort changes in the mean levels of lifetime earnings and retirement wealth over time. We included Social Security wealth, DB wealth, ${ }^{15}$ DC account balance, and IRA as retirement wealth, as they are expected to generate income upon retirement. For this reason, the value of other household assets was excluded. ${ }^{16}$ The two vertical axes were drawn at a 4:1 scale (roughly the ratio of lifetime income to assets in 1992 and 1998), so that at any horizontal line, the amount of lifetime earnings (in 2010 USD) is always four times of the retirement wealth (also in 2010 USD). Furthermore, if the retirement wealth trend is steeper (flatter) than the lifetime earnings trend, it indicates retirement wealth grows faster (slower) than the lifetime earnings.

It is clear from the graph that retirement wealth did not keep pace with lifetime earnings overtime. Among those who were age 51-56, retirement wealth has consistently decreased relative to lifetime earnings since 1992. While lifetime earnings kept growing for the younger cohorts, retirement wealth actually decreased after peaking in 1998. In the bottom panel of Figure III, we added the retirement wealth found through plan documents but not reported by the

\footnotetext{
15 “DB wealth” here includes prorated wealth from current job (to reflect the benefits that already accrued) as well as the wealth in dead/dormant plan from past jobs. The latter component was brought in from the updated pension sequence as in Gustman, Steinmeier, and Tabatabai (2010a).

${ }^{16}$ The value of household asset, in which the biggest component is the house itself for the majority of the population, largely stayed at a same level over time (Table I), except for the housing boom in the mid-2000. Including household asset hence will not change the trend in retirement wealth but could potentially overstate the present value of the retirement income.
} 
respondents in 2010 onto the graph (the calculation is shown in Table V). That raised the retirement wealth for the 2010 cohort to the 2004 level, but still at a much lower level in absolute and relative terms comparing to the earlier cohorts. Hence, although the newly available data and method allowed us to better capture the pension wealth of HRS respondents in 2010, reporting errors seemed to only explain a small portion of the cohort changes at best.

Figure IV shows the changes by gender. Lifetime earnings for men peaked in 2004, and lifetime earnings for women have been increasing over time. Despite the increased earnings, however, the retirement wealth did not grow as fast (for women) and even declined (for men). Figure V shows the changes by race. The earnings and retirement wealth across racial groups peaked at various times, but the patterns were largely the same. Regardless whether we look at the whole sample, by gender, or by racial groups, retirement preparation among the American near-elderly (at least when measured in financial wealth) seems to have weakened since the turn of this century.

The trends in each component of the retirement wealth are shown in Figure VI. The shift from DB to DC over time is clear; however, the increase in DC and IRA combined has not been able to offset the decline in DB wealth. Social Security wealth slightly increased overtime. Hence, Social Security is playing a more important role in the retirement wealth of the younger cohort. This conclusion holds across gender and racial groups (Figures VII and VIII). If anything, racial minorities were more adversely affected by the decline of defined benefit plans; as a result, racial minorities in the recent cohorts will have to rely more on Social Security than their earlier peers.

\section{B. Cohort Changes along the Distribution}


We further explored how the decline in retirement wealth affected the population across the earnings and wealth distribution. The policy implication likely will be different if the decline in retirement wealth was a mean-shift rather than, for example, concentrated on a certain part of the distribution. Additionally, to the extent that the composition of population ages 51-56 has changed over time, ${ }^{17}$ we also wanted to differentiate the change in retirement wealth accumulation from the change in population composition.

To do so, we used the semiparametric variance decomposition method developed in DiNardo, Fortin, and Lemieux (1996, hereafter DFL). In addition to decomposing the changes in retirement wealth into the "compositional effect” (change in the distribution of retirement wealth that can be attributed to the change in the distribution of population characteristics) and the "structural effect” (change that cannot be attributed to the changing population characteristics) (Fortin et al., 2011), the DFL decomposition also allows the magnitude of change to vary across the whole distribution. In this paper, we omit the technical details of the decomposition and only present the steps that led our findings.

We focused our analysis on the cohort changes between 1998 and 2010, the period during which the retirement wealth declined significantly according to Figures III through VIII. The three parts in Figure IX shows the decomposition of changes in retirement wealth in 1998-2004, 2004-2010, and 1998-2010. The top-left part of the 1998-2004 graph has two curves: the distribution of retirement wealth in 1998 (maize line) and a "weighted” distribution of retirement wealth in 1998 (blue line). The blue distribution is weighted in a way that the distribution of

\footnotetext{
${ }^{17}$ The population is becoming more educated and racially-diverse, and women also have higher levels of labor force participation. The imputed lifetime earnings should capture some, but not all, of the variations associated with the compositional change.
} 
sample characteristics in 1998 is the same as that of 2004. ${ }^{18}$ In other words, the blue distribution is how the retirement wealth would have been distributed in 1998 had the distributions of HRS sample characteristics stayed the same in 1998 and 2004. In the top-right part, the maize line is the distribution of retirement wealth in 2004, and the blue line is the same weighted 1998 distribution as in the top-left part. If, after adjusting for the changes in sample characteristics, the 1998 and 2004 distributions were identical, the maize and blue lines should overlap in the top-right panel. Any deviation between the two lines indicates the changes in the distribution of retirement wealth that cannot be attributed to the population change overtime. The difference between these two lines is presented in the bottom-left part. It would have been a horizontal line at zero had the two lines in the top right panel perfectly overlapped. However, the bottom-left panel in the 1998-2004 graph shows that the distribution of retirement wealth somewhat "polarized" between 1998 and 2004. In 2004, the age 51-56 population was more likely to have retirement wealth at lower part of the distribution (logarithm of wealth around 9 and 11) as well as the higher part (logarithm of wealth around 13), but less likely to have wealth in between (logarithm of wealth around 11 and 13), compared to the population in 1998. The bottom right panel is the same as the bottom-left panel but without taking logarithm, which shows the same polarization—a larger mass shifted to the lower end of the distribution while a smaller mass shifted upward from 1998 to 2004.

The interpretations of the other DFL decompositions graphs are similar. In the 20042010 graph, we show that the shift in retirement wealth was downward. In the final graph, 19982010, the decline in retirement wealth is clear. Overall, those who were age 51-56 in 2010 were more likely than their 1998 counterpart to have retirement wealth between $\$ 20 \mathrm{~K}$ and $\$ 200 \mathrm{~K}$

\footnotetext{
${ }^{18}$ The sample characteristics considered include: gender, race, level of education, marital status, region of residence, labor force participation, disability, home ownership, and lifetime earnings.
} 
(logarithm of wealth between 10 and 12), but less likely to have wealth between $\$ 200 \mathrm{~K}$ and \$1.2M (logarithm of wealth between 12 and 14). While the retirement wealth of the 2010 cohort likely was hurt during the Great Recession and likely will rebound, the magnitude of cohort changes shown in the DFL decomposition is much larger than the effect of stock market decline found in Gustman, Steinmeier, and Tabatabai (2010b). Hence, the evidence from DFL decomposition is consistent with the mean trend, and suggests the 2010 cohort likely will not be as financially prepared as the earlier cohorts upon retirement.

\section{VALIDITY OF EARNINGS PROJECTION}

The HRS estimations of Social Security and DB wealth in the public release file relied on two assumptions about labor force participation and earnings. To estimate the Social Security wealth, we assumed that: (a) the respondent stays in the labor force between the time the estimates were calculated and the time of retirement; and (b) the earnings profile stays on the same linear trajectory. ${ }^{19}$ More specifically, the HRS adopted and modified the earnings projection method in Mitchell, Olsen, and Steinmeier (2000). The projected earnings in year $T$, $Y_{T}$, is a weighted average of earnings in the past five years:

$$
Y_{T}=\left(1+C P I_{T}\right) \times \frac{1}{15} \sum_{t=1}^{5}\left((6-t) \times Y_{T-t} \times \frac{A W I_{T-1}}{A W I_{T-t}}\right)
$$

\footnotetext{
${ }^{19}$ Although in this paper we only included the Social Security wealth based on the earnings history before respondents entered the HRS (and hence no need to impute earnings for those whom we have earnings records), for those with linked earnings records, projected earnings still is relevant because we do not have linked earnings records for every respondent. For the respondents with no or incomplete earnings records, we used their imputed early retirement benefits (which were imputed with nearest neighbor matching, with the earnings among those who had linked earnings records projected through age 62) and prorated those numbers.
} 
$C P I_{T}$ is the change in consumer price index between year $T-1$ and year $T$. AWI is the average wage index used by SSA to calculate Social Security benefits. The projection was done iteratively until the age of retirement.

To estimate pension wealth, we only relied on one earnings data point for each respondent (self-reported earnings in wave when pension wealth was estimated), so we imposed a more strict assumption that all respondents' earnings profiles followed the same linear trajectory. The nominal annual earnings growth used in 2004 was $4 \%$.

\section{A. Earnings Projection and Social Security Wealth}

Using respondents with the linked earnings records, we examined the validity of earnings projection by comparing the actual/realized earnings versus the earnings that would have been projected in an earlier period based on our method. To the extent that projected earnings were different from actual earnings, we also assessed the impact of errors in earnings projection on Social Security benefits.

Figure $\mathrm{X}$ shows the earnings projection by the level of education. In the top panel of Figure $\mathrm{X}$, the solid lines are the (weighted) mean earnings by the level of education between 1992 and 2003, for HRS respondents who were ages 51-56 in 1998 and whose SSA-linked earnings records were available through at least 2003. We dropped those who never reported to be working between 1998 and 2003. The dashed lines are the mean of earnings that were projected using earnings history up to 1997 (i.e., the earnings that would have been projected in 1998). The difference between solid and dashed lines of the same color represents the error in the earnings projection: the difference between actual earnings in 1998-2003 and the earnings that would have been projected in 1998 using linked earnings records through 1997. The lower panel does the similar thing for the HRS cohort ages 51-56 in 2004, with the baseline year 
shifted six years from the top panel. We do not yet have the linked data to construct a similar analysis for the 2010 HRS cohort.

Figure $\mathrm{X}$ suggests that the errors in earnings projection for ages 57-62 were larger for the later cohort than the earlier cohort, likely due to the Great Recession. While the 1998 projection worked pretty well, except for those who were high school graduates or less, the errors in the 2004 projection were large across all education groups. We also have tried some other variables in 2004; nevertheless, there did not seem to be a variable known/observed in 2004 that could strongly predict the size of projection error six years later. Nevertheless, we need to point out that, by definition, earnings projection was only supposed to project the earnings, assuming the respondent stays in the same earnings trajectory until retirement and was not meant to "predict" major macroeconomic events.

Figure XI follows a similar logic, but instead the respondents were categorized by whether they were working full time at the end of the 12-year period in each panel. The earnings projection as of 1998 worked fine for those who were still working full time in 2004, as well as those who were not working in 2004. However, the projection error was large for those who were working part-time in 2004. The lower panel in Figure XI further splits the "working full time in 2004" group into same employer in 1998 and 2004 and different employer in 1998 and 2004. Overall, the quality of earnings projection was not related with whether the respondent changed employer or not during 1998 and 2004. Nevertheless, Figure XI shows that the size of projection error increased when our underlying assumptions (that the respondent stayed in the labor force and on the linear earnings trajectory) did not hold. While we cannot tell the nature of changing labor supply in this figure, the size of projection error due to changing labor supply 
will have a much larger impact on the analysis of retirement preparation if the reduction in labor supply is involuntary rather than voluntary.

Figure XII is similar to Figure XI, except that it compares outcomes to 2010 with 2004 projections. However, in Figure XII, the effect of the Great Recession is pronounced. The projected earnings were always lower than the actual earnings six years out, regardless whether the respondent was working full-time, part-time, or not working at all. The further analysis in the lower panel of Figure XII shows that, when we split the respondents by whether they changed employers in 2004 and 2009, most of the projection errors were concentrated among those who changed employers. Furthermore, those who were still working full-time but for different employers actually had similar pre-2004 earnings history as those who were not working in 2010, an indication of a significant level of involuntary reductions in labor supply among those who were not working in 2010.

Hence, the earnings projection used to estimate Social Security wealth performed reasonably well among those who stayed in the same job during both periods. It did not perform as well for the respondents who changed jobs. Nonetheless, given the rationale of and underlying assumptions behind earnings projection, earnings changes due to job change and/or the Great Recession should be interpreted as negative shocks to the earnings rather than shortcomings of the earnings projection.

How do the errors in earnings projection in Figures X through XII translate into our estimates of Social Security benefits wealth? Theoretically, that depends on the level of earnings throughout earlier years of the life cycle. Because the Social Security system is regressive, the impact of errors in earnings projection on benefits would be larger if, at the margin, the errors 
fall on the lowest segment of the AIME-PIA relationship (where the replacement rate is 0.9) than on the higher segments (where the replacement rates are 0.32 or 0.15 ).

We used SSA’s ANYPIA program to calculate HRS respondents’ PIA at different retirement/quitting ages under actual and projected earnings profile. Panel A of Table VII is the PIA of male HRS respondents who were ages 51-56 in 1998, calculated using (a) actual earnings through 1997 and projected earnings between 1998 and 2003, and (b) actual earnings through 2003, assuming the respondents quit working in the end of 2003 and claimed old age benefits as soon as they became eligible at age 62. Panel B of Table VII is the PIA of the same group calculated using (a) actual earnings through 1997 and projected earnings between 1998 and normal retirement age, and (b) actual earnings through 2003 and projected earnings between 2004 and normal retirement age, assuming the respondents continued working and claimed the benefit when they hit the normal retirement age. Panels $\mathrm{C}$ and $\mathrm{D}$ show the corresponding numbers for male HRS respondents ages 51-56 in 2004. Hence, the difference across columns in Table VI reflects the effect of errors in earnings projection on PIA (and hence Social Security wealth, since any change in PIA would change wealth in the same proportion, everything else being equal) at retirement.

For the 1998 cohort men, the benefit estimates based on projected earnings are not very different from those based on actual earnings. The difference is less than $2 \%$ across all subgroups (Panels A and B in Table VII). For the 2004 cohort men, the difference across columns is larger, especially for those who were not working in 2010. The higher-than-actual projected earnings overstated the estimated Social Security wealth based on projected earnings for those who worked less than full time in 2010, and the magnitude of overstatement increased with claim age. At the full retirement age, wealth estimates based on earnings records through 
2003 (and projected earnings after that) overstated the Social Security wealth by 5\% among those who were not working in 2010. ${ }^{20}$

Table VIII shows the same set of comparisons for female HRS respondents. Panels A and B in Table VIII suggest that the projected earnings led to reasonably good estimates of Social Security wealth. If anything, the earnings projection might have slightly understated women's late career earnings. It is also important to point out that, by staying in the labor market until the full retirement age (Panel B, compared to Panel A), women in the 1998 cohort were able to raise their lifetime earnings substantially (which likely reflected the lower level of labor force participation earlier in the career) and have significant gains in their Social Security wealth. The effect of "catch-up" was smaller for the 2004 cohort (Panels C and D; however, the 2004 cohort had higher level of wealth in the lower end of distribution than the 1998 cohort). The earnings projection, in general, slightly understated Social Security wealth for women wo were still working in 2010, but overstated for women who were not working in 2010.

Overall, the earnings projection performed better for the 1998 cohort than the 2004 cohort. For the 2004 cohort, the earnings projection as of 2004 did not capture the negative earnings shocks many respondents experienced during the Great Recession. ${ }^{21}$ Nevertheless, except for the respondents who were not working as of 2010, the errors in earnings projection did not lead to very large bias in the estimation of Social Security wealth. Among the HRS

\footnotetext{
${ }^{20}$ In this paper, we are namely concerned how the errors in earnings projection affect our estimate of retirement wealth. An economic shock, positive or negative, could change retirement wealth not only though earnings (and hence DB and Social Security wealth), but also directly through the prices of other investments and household assets. This has been discussed in the literature (for example, see Gustman, et al., 2010b; Munnell and Rutledge, 2013) and is beyond the scope of our paper.

${ }^{21}$ It will be interesting to see how the earnings projection as of 2010, which was at the trough of the recession in terms of employment and earnings, compare against the eventual earnings profile and how this affects the estimation of Social Security wealth and retirement preparation. We are not able to make such comparisons until the linked earnings records for more recent years become available.
} 
respondents who stayed with the same employer, projected earnings were very close to actual earnings, regardless the macroeconomic conditions. Hence, the projection worked well for respondents whose labor supply was consistent with the "staying with the same employer until retirement” assumption in the earnings projection. For the respondents whose labor supply deviated from that assumption, the effect of earnings projection errors on Social Security wealth was alleviated by the regressive schedule of Social Security benefit calculation. Even in the worst-case scenario, the wealth estimate was only off by about $5 \%$ at the mean.

\section{B. Earnings Projection and Pension Wealth}

In theory, errors in earnings projection will have a larger effect on DB pension wealth. First, the formula to calculate DB wealth is not regressive, so any error in earnings projection will lead to the same change (percentage-wise) in DB wealth among the respondents who stayed with the same employers and whose plan provisions remained unchanged. Second, DB wealth formula is usually back-loaded; for respondents who switched jobs, they would not only miss the "kinks" in the benefits formula had they stayed in the same job but also start at lower segment of the benefit formula in the new job. If the job change was accompanied with lower-thanprojected salaries or if the respondent quit earlier than expected, the respondent's DB wealth could be significantly overstated.

Since the Pension Wealth Estimation program relied on the earnings at the baseline wave to project the earnings at various retirement timings, it assumed the earnings growth was the same across the sample and over time. Summary statistics of actual 2004 earnings (from the 2004 pension wealth estimates data), projected 2010 earnings (based on actual 2004 earnings), and actual 2010 earnings (from the 2010 pension wealth estimates data) are listed in Table IX. In 2004, only those who had coded pension plans had projected 2010 earnings in the Pension 
Wealth Estimation program output. ${ }^{22}$ Overall, among those who stayed in the same job, earnings projection as of 2004 overshot by $10 \%$ for men and $15 \%$ for women at the mean. ${ }^{23}$ The earnings projection error was smaller for respondents in the private sector than those in the public sector. Projection errors in earnings for those who left their 2004 employer (either for a different employer in 2010 or out of work) were even larger. Figure XIII show the distribution of earnings projection errors. A vertical line was drawn where the annual growth equals $4 \%$. In 2004, the HRS assumed a nominal earnings growth rate of $4 \%$ each year, but most respondents experienced slower earnings growth between 2004 and 2010. A comparison of actual earnings data between 2004 and 2010 suggests the earnings growth was only about $2.5 \%$.

In Table X, we show how the earnings projection errors in Table IX affected pension wealth. Due to the small number of respondents whose plans were coded in both 2004 and 2010, the point estimates were a bit noisy. Numbers in the first column are the age 65 DB wealth estimates as of 2004, inflated to 2010 U.S. dollars. DB wealth estimates as of 2010 are reported in the second and third columns, which have slightly different meanings across rows. Numbers in the second column are the wealth estimates accrued when the respondents left their 2004 job, evaluated at the year of job separation and inflated to 2010 U.S. dollars. Hence, the difference between the first two columns reflects the wealth loss due to early separation from the job. Numbers in the third column are the age 65 DB wealth estimates as of 2010 for the 2010 job, which would be the same jobs for those who stayed with the same employer, but new 2010 jobs for those who changed employers. The sum of the second and third columns hence reflects the

\footnotetext{
${ }^{22}$ Rather than feeding earnings into imputed plans (as in 2010), in 2004 HRS imputed the wealth directly for those whose plans were not matched and coded.

${ }^{23}$ Part of the big errors at the mean is driven by a few outliers (see Figure XIII). At the median, the error is about $5 \%$ for both genders.
} 
DB wealth estimates as of 2010. The final column is the difference between wealth estimates in 2004 and 2010, and reflects how pension wealth estimates were affected by earnings projection errors and/or job changes.

Numbers in Table X show that, DB wealth in 2010 was 10\% to 20\% lower than in 2004 among those who stayed in the same public sector job. Since these respondents (ages 57-62 in 2010) were much closer to retirement in 2010, there may not be enough time for their earnings to get back to the level projected in 2004. Hence, while the comparison is relative rather than absolute, it is more likely that the 2004 wealth was overstated than the other way around (that the 2010 wealth was understated). For both men and women in the same private sector jobs, DB wealth increased at the mean. However, this is driven by a few outliers at the lower end of the distribution in 2004. The median and trimmed-mean (excluding the outliers) wealth stayed roughly at the same level across the two periods, reflecting the smaller earnings projection errors for this group of HRS respondents (see Table IX).

We suspect there could be some self-selection among those who changed employers: whether respondents quit their 2004 job voluntarily or not may be correlated with how their DB wealth compared in 2004 and 2010. The group that quit their 2004 pension job and had a nonpension job clearly saw a big reduction in wealth. For the other two groups who quit their pension job in 2004, the wealth difference was smaller relative to the level of wealth. Although in theory HRS respondents could miss the "kinks" in back-loaded pension plans by quitting early, it is also likely that some respondents might have plans from their career jobs in which the maximum return occurred at about age 60. In this latter scenario, the respondents would be better off just quitting the 2004 job before 2010 (taking either early retirement or vested-deferred option) rather than staying until age 65, especially among those who already had long job tenure. 
They still would receive similar or even higher wealth (measured in present discount value) from the 2004 job, with an option to take a new job as the transition into retirement. Unfortunately, due to the small sample size, we do not have enough statistical power to test such hypothesis. The fact that women who quit their jobs before 2010 on average lose pension wealth is nevertheless consistent with this selection mechanism, as women in this cohort tend to have shorter tenure due to the interruptions in their labor market participation.

Table XI shows the wealth estimates at the expected retirement age. The expected retirement age may differ across respondents, across jobs for the same respondent, and may even differ over time within the same respondent-job. The patterns are largely the same as in Table X, but the magnitudes of errors are smaller. Possible explanations are that the variations in kinks of the benefit schedules are reflected in subjective expectations of retirement age, and respondents may also change expected retirement age to compensate the benefit loss.

To summarize, the earnings projection in pension wealth estimation as of 2004 overstated the actual earnings in 2010, even among those who had the same job. This led to lower pension wealth estimates in 2010 than in 2004, especially among the male public sector employees, by about $10 \%$. The effect of earnings projection error on pension wealth among job switchers is theoretically ambiguous. The effect may be negative if respondents miss the "kinks" in the backloaded pension plan by quitting early and start new jobs at lower earnings. However, for those who already had long seniority and hit the maximum return in the pension plan, they may receive similar or higher total pension wealth if they retired before 2010 than stayed in the same job until age 65. The error in earnings projection will have much smaller impact for such respondents. This leads to a hypothesis that the effect of earnings projection error on wealth among job switchers depend on whether the job separation is voluntary. We do not have enough statistical 
power to test such hypothesis due to the small number of respondents whose plans were coded in 2004 and 2010.

\section{Comparing Two Methods of Earning Projection}

The earnings projection for Social Security wealth estimation relied on individualspecific earnings trajectory based on earnings history, and the earnings projection for pension wealth estimation relied on a fixed earnings growth rate across all individuals. The former allows variations in earnings growth rate both across individuals and over time; the latter does not allow such variation, but is much easier to implement (each researcher can use her own assumption). Additionally, the earnings projection in pension wealth estimation requires much less data-it only requires one data point per respondent, while the individual-based projection requires the earnings history and, hence, cannot be directly implemented for the respondents whose Social Security earnings are not available. ${ }^{24}$

Based on our findings in Sections VI.A, the earnings projection based on linked Social Security earnings performed pretty well among those who stayed with the same employer. The errors were larger for those who switched jobs or quit from the labor market. However, the motivation behind the earnings projection is to estimate the retirement wealth based on the assumption that the respondent stays in the same job until the retirement age. The earnings changes due to job changes and/or the Great Recession should hence be more appropriately

\footnotetext{
${ }^{24}$ For the purpose of wealth estimation, there are two solutions for those whose earnings records were unavailable or incomplete. The first is to impute wealth directly based on earnings reported in the HRS as well as other individual and job characteristics, as the HRS has done. The second is to impute earnings history based on the earnings reported in the HRS and a hypothesized earnings profile (for example, using the parameters and profiles identified in Guvenen (2009) or Guvenen, Karahan, Ozkan, and Song (2015)), then use the imputed earnings history to calculate wealth.
} 
considered as shocks to the earnings trajectory rather than the shortcoming in the earnings projection method itself.

Section VI.B suggests the projection based on one data point and a homogenous earnings growth rate tend to have bigger errors. Even for the respondents who stayed in the same job between 2004 and 2010, the projection errors are larger than those in the projections using Social Security earnings records. Nevertheless, it does not mean this method is necessarily inferior. This method is easier to implement and requires much less data. Furthermore, this method would have performed equally well, at least at the mean, had the earnings growth rate been set at $2.5 \%$ rather than $4 \%$ in 2004 . Hence, for researchers who do not have access to the restricted Social Security earnings data, using a linear projection with a universal earnings growth rate can still lead to satisfactory results, especially if a set of sensitivity analysis is performed based on a reasonable range of earnings growth rates rather than just one fixed assumption.

The selection of earnings projection likely depends on the research question, method, and whether the researcher has access to restricted Social Security earnings data. Each method has its pros and cons, so there will be a trade-off depending on the context. For example, although the projection that relied on Social Security earnings history performed better, this method may significantly complicate the computation in a structural model type of setting due to the additional state variables required to keep track of past earnings. On the other hand, the projection that assumes a universal earnings growth rate can be implemented in a much easier manner.

\section{CONCLUSION}

This paper intended to answer three questions. First, how do the newly available data sources enrich our understanding about the pension wealth held by HRS respondents and 
improve our assessment of retirement wealth? Second, how does the improved data inform about the financial preparedness for retirement among Americans from the middle of the baby boom? Third, how much does the estimation of retirement wealth depend on the assumption about earnings projection?

The newly available plan information publicly available from the Department of Labor's Form 5500 database enabled us to better capture the provisions of pension plans in the private sector. We were able to match almost $90 \%$ of DB plans that HRS respondents who worked in the private sector reported to have, in addition to virtually all the DB plans in the public sector. The decision to code all the plans that can be matched was justified by the substantial variation in plan wealth both across and within sectors, holding individual and job characteristics constant. Public plans tend to provide higher levels of benefits. Plans in the private sector that were frozen or taken over by PBGC had lower levels of benefits compared to other private sector plans. Hence, the newly available plan information improved our understanding of retirement wealth in three ways: It reduced the need for imputation, it captured the variation in plan generosity, and it allowed us to identify plans not reported in the survey. We found that most the pension wealth was associated with plans where the self-report and Form 5500 data were consistent. Wealth in plans where self-report and Form 5500 data did not agree were relatively small. Additionally, the linked W-2 earnings records also provided information on DC plan participation. Combining all these data sources, we concluded that about $10 \%$ of pension wealth was missed from the selfreport in the HRS.

We also documented the cohort changes in pension wealth over time. Overall, retirement wealth has declined after the turn of the century, in both absolute and relative (to lifetime earnings) terms. The magnitude of decline was larger than what can be explained by report error 
or the effect of Great Recession, suggesting the near-elderly population in the recent cohort was not as financially prepared as their earlier peers when approaching retirement. The shift from DB plans to DC plans and/or IRA has, on average, reduced the retirement wealth, as the gain in DC/IRA has not been enough to offset the loss in DB wealth. As a result, Social Security wealth was also becoming a bigger component of retirement wealth for recent cohorts, especially among the minority. From the policy perspective, this indicates the solvency of the Social Security system could potentially have more severe consequences on those financially vulnerable.

Finally, we compared the earnings projections methods used to estimate Social Security and pension wealth. The earnings projection used for Social Security wealth requires linked W-2 earnings history, and allows individual heterogeneity in earnings growth, as well as variations in earnings growth over time. The earnings projection used for pension wealth only requires one data point for each respondent and assumes one universal earnings growth rate. We found that the first method worked reasonably well among those who stayed in the same job. The projection errors were larger among those who switched jobs. The second method, on average, slightly overstated future earnings, at least in 2004. However, while this method may be subject to larger errors potentially, it can be compensated by estimating the results of interest using a range of reasonable earnings growth rates as a sensitivity analysis. The choice of earnings projection method hence depends on the context of the research setting, such as the research question itself (Is earnings projection the end or just the means to obtain another set of result?), access to restricted data (does the researcher have access to the linked earnings history? How many cases have no or incomplete earnings history and require imputation?), and the research method used (Does the method have the capacity to include the full earnings history or can only accommodate a certain earnings process with given parameters?). 


\section{REFERENCE}

DiNardo, John, Nicole M. Fortin and Thomas Lemieux. 1996. "Labor Market Institutions and the Distribution of Wages, 1973-1992: A Semiparametric Approach." Econometrica, 64(5), 1001-44.

Dushi, Irena and Marjorie Honig. 2015. "How Much Do Respondents in the Health and Retirement Study Know About Their Contributions to Tax-Deferred Contribution Plans? A Cross-Corhort Comparison." Journal of Pension Economics and Finance, 14(3), 20379.

Fang, Chichun, Amy Butchart, Helena Stolyarova, Michael Nolte and Bob Peticolas. 2016. "Pension Estimation Program User's Guide." HRS Data User Guide.

Fang, Chichun and Kandice Kapinos. 2016. "Health and Retirement Study: Prospective Social Security Wealth Measures of Pre-Retirees, Wave 10." HRS Data User Guide.

Fortin, Nicole M., Thomas Lemieux and Sergio Firpo. 2011. "Decomposition Methods in Economics," O. Ashenfelter and D. Card, Handbook of Labor Economics. 1-102.

Gustman, Alan L., Thomas L. Steinmeier and Nahid Tabatabai. 2010a. Pensions in the Health and Retirement Study. Harvard University Press.

Gustman, Alan L., Thomas L. Steinmeier and Nahid Tabatabai. 2010b. "What the Stock Market Decline Means for the Financial Security and Retirement Choices of the nearRetirement Population." Journal of Economic Perspectives, 24(1), 161-82.

Guvenen, Fatih. 2009. "An Empirical Investigation of Labor Income Processes." Review of Economic Dynamics, 12(1), 58-79. 
Guvenen, Fatih, Fatih Karahan, Serdar Ozkan and Jae Song. 2015. "What Do Data on Millions of U.S. Workers Reveal About Life-Cycle Earnings Risk?" NBER Working Paper 20913.

Kopczuk, Wojciech, Emmanuel Saez and Jae Song. 2010. "Earnings Inequality and Mobility in the Unites States: Evidence from Social Security Data since 1937." Quarterly Journal of Economics, 125(1), 91-128.

Mitchell, Olivia S., Jan Olson and Thomas L. Steinmeier. 2000. "Social Security Earnings and Projected Benefits," O. S. Mitchell, P. B. Hammond and A. M. Rappaport, Forecasting Retirement Needs and Retirement Wealth. University of Pennsylvania Press,

Munnell, Alicia H. and Matthew S. Rutledge. 2013. "The Effects of the Great Recession on the Retirement Security of Older Workers." Annals of the American Academy of Political and Social Science, 650(1), 124-42.

US Department of Labor, Employment Benefits Security Administration. 2012. "Private Pension Plan Bulletin: Abstract of 2010 Form 5500 Annual Reports."

Wasi, Nada and Aaron Flaaen. 2015. "Record Linkage Using Stata: Pre-Processing, Linking and Reviewing Utilities." Stata Journal, 15(3), 672-97. 
Figure I: Plan Generosity by Sector

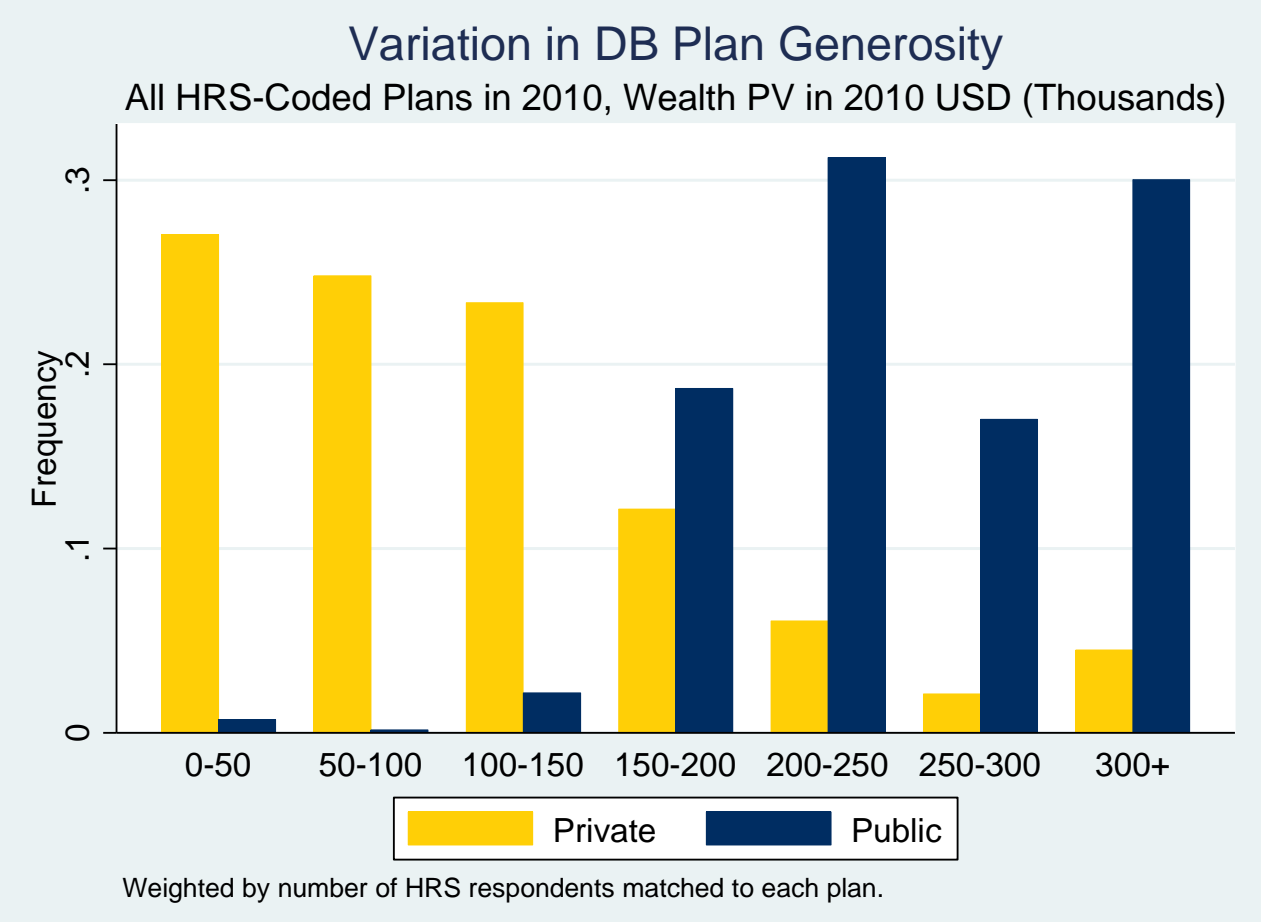


Figure II: Plan Generosity by Frozen Status, Private Sector

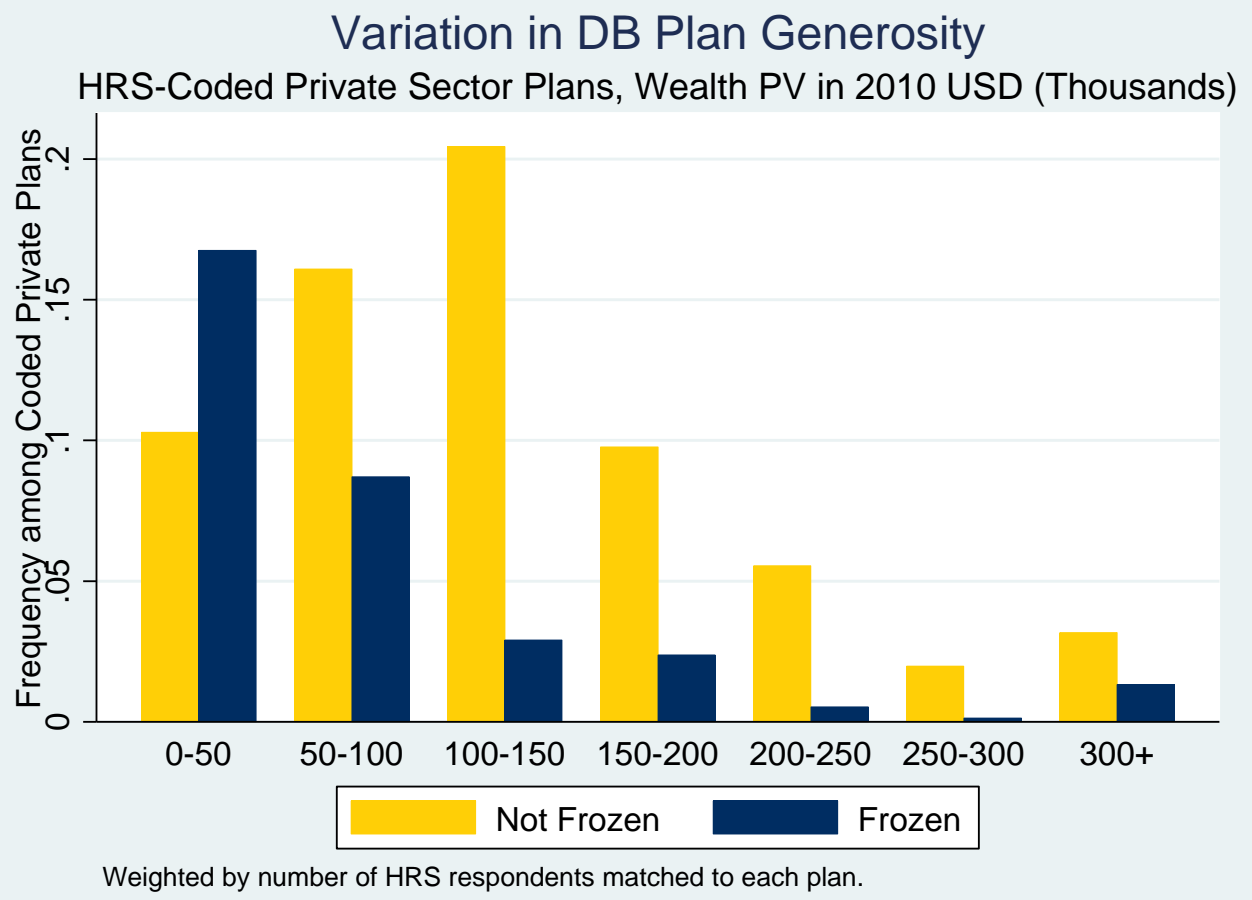


Figure III: Cohort Changes in Lifetime Earnings and Retirement Wealth

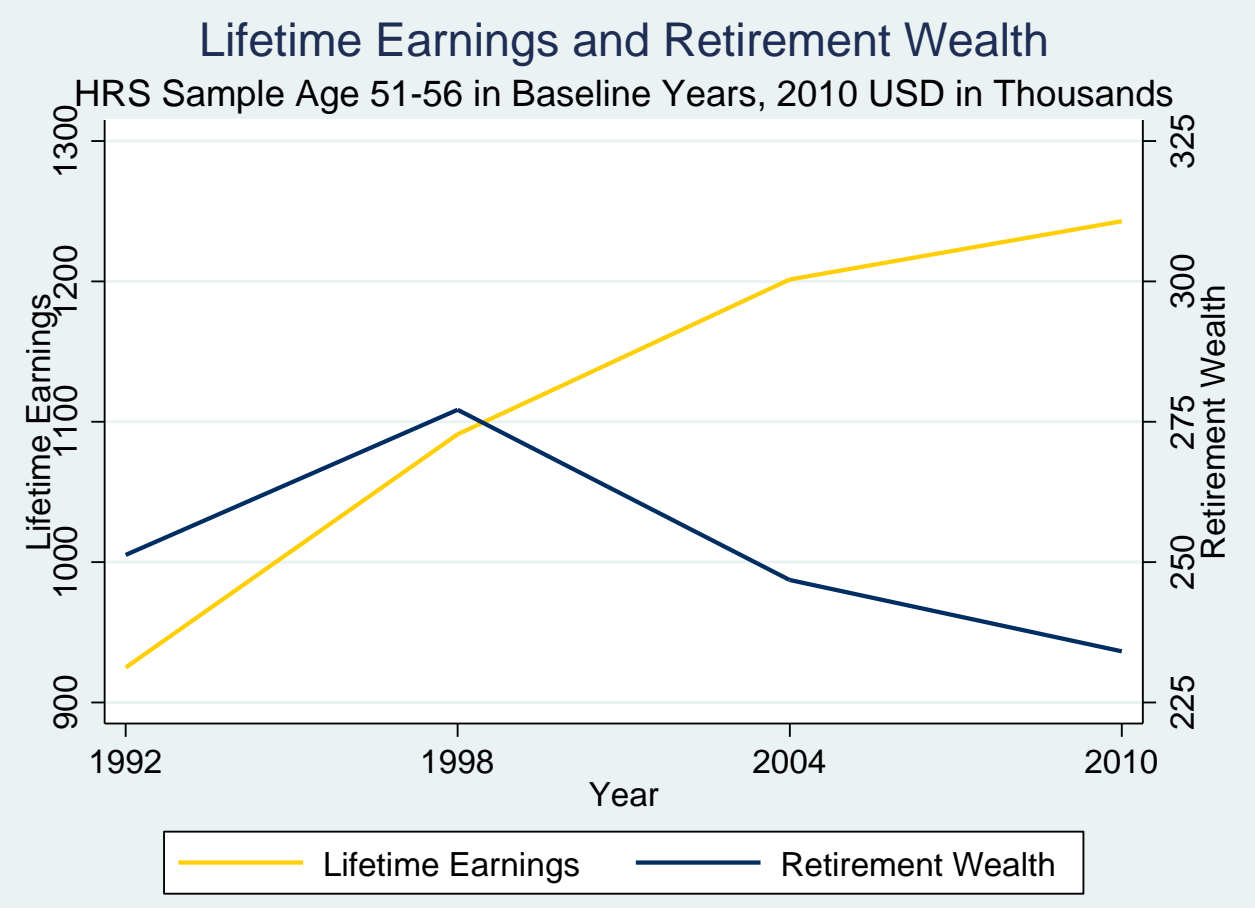

Lifetime Earnings and Retirement Wealth

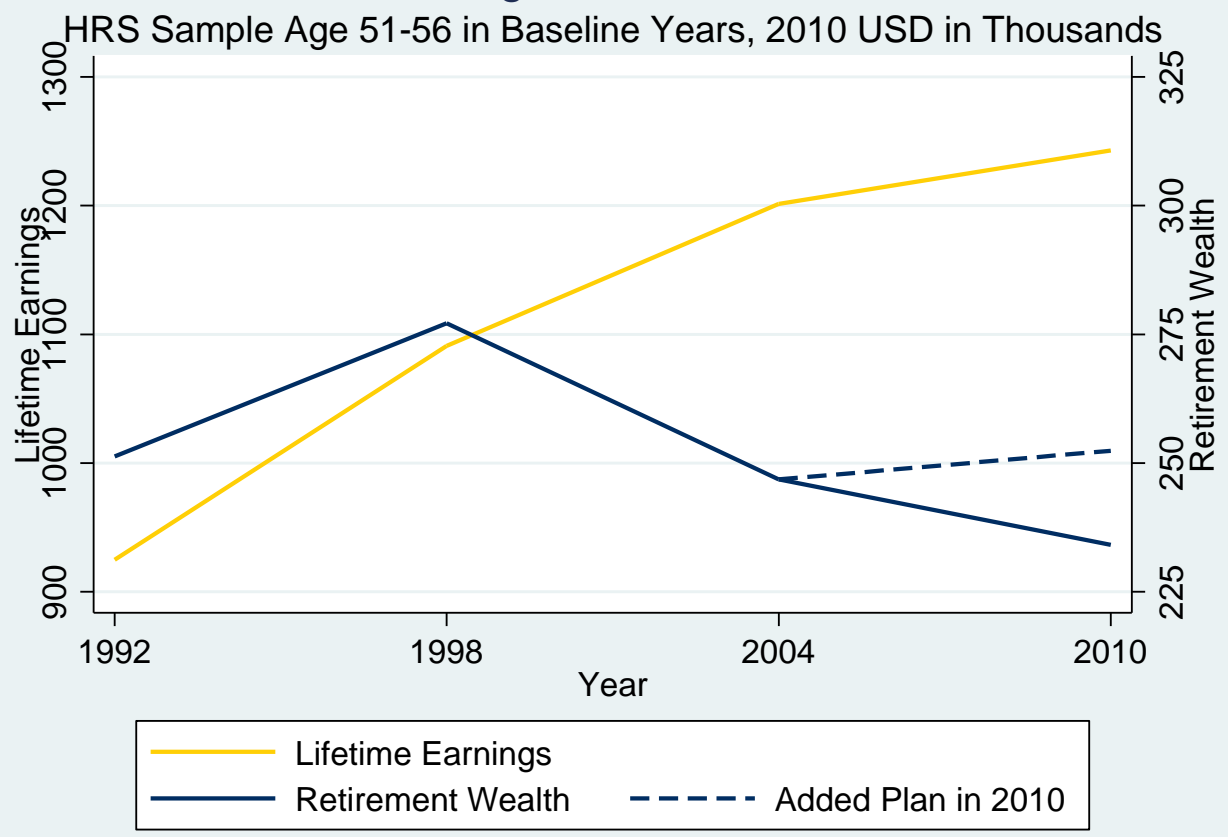


Figure IV: Cohort Changes in Lifetime Earnings and Retirement Wealth, by Gender

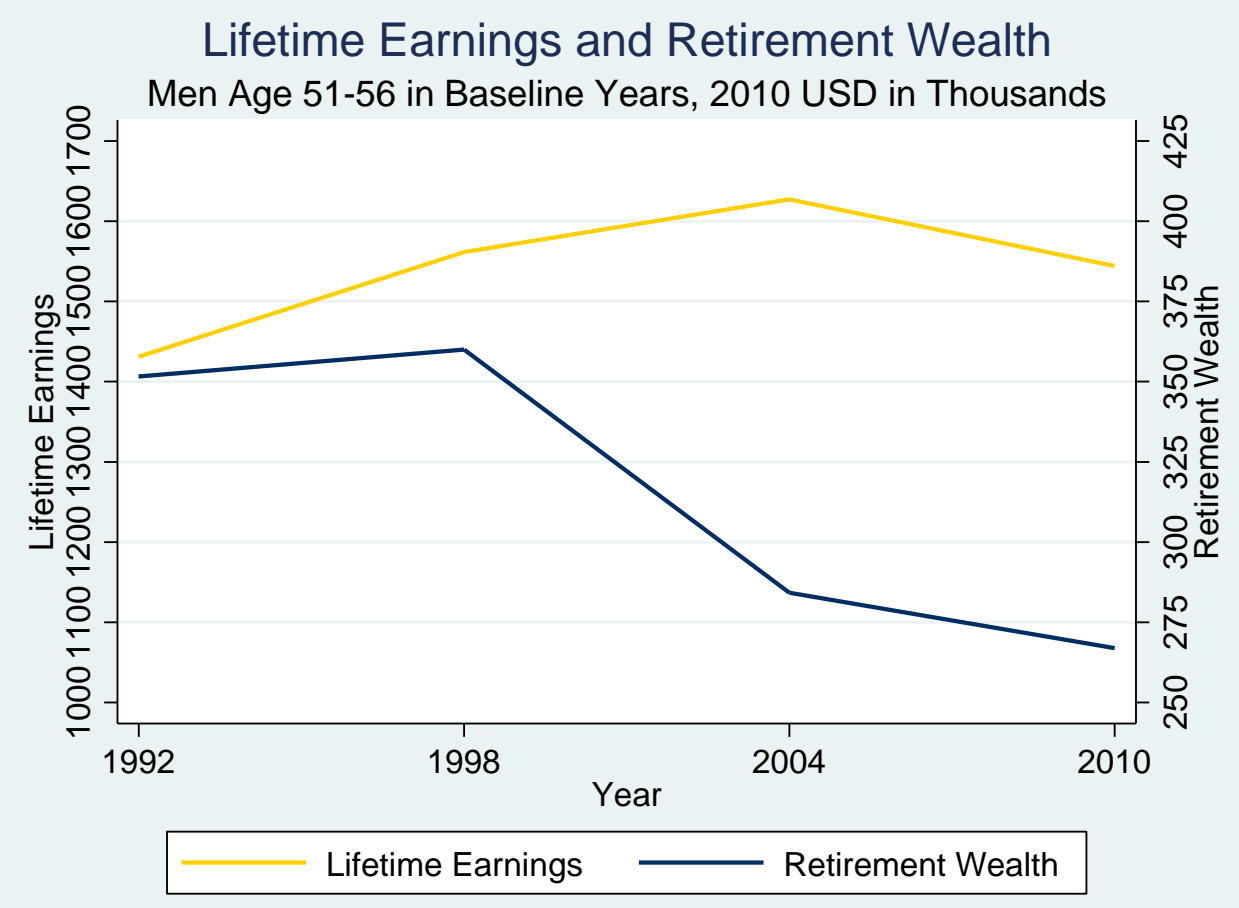

Lifetime Earnings and Retirement Wealth

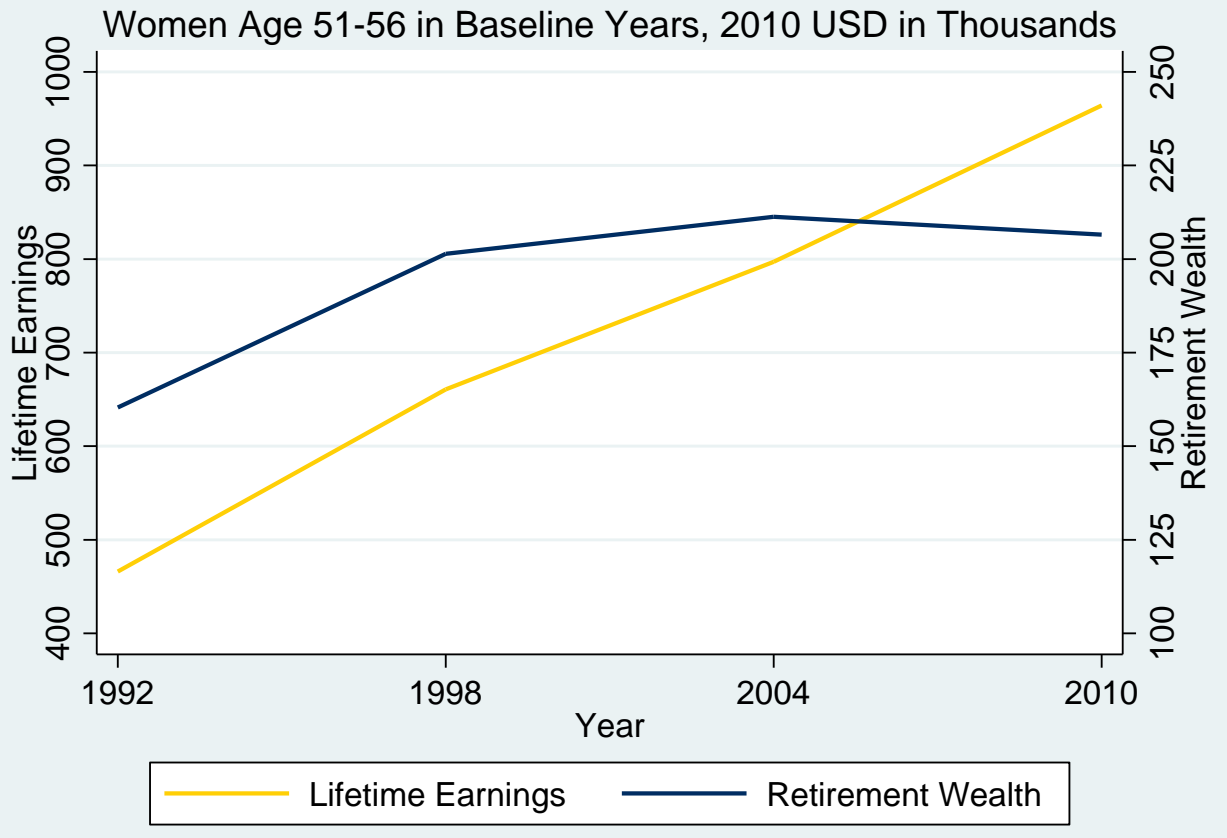


Figure V: Cohort Changes in Lifetime Earnings and Retirement Wealth, by Race

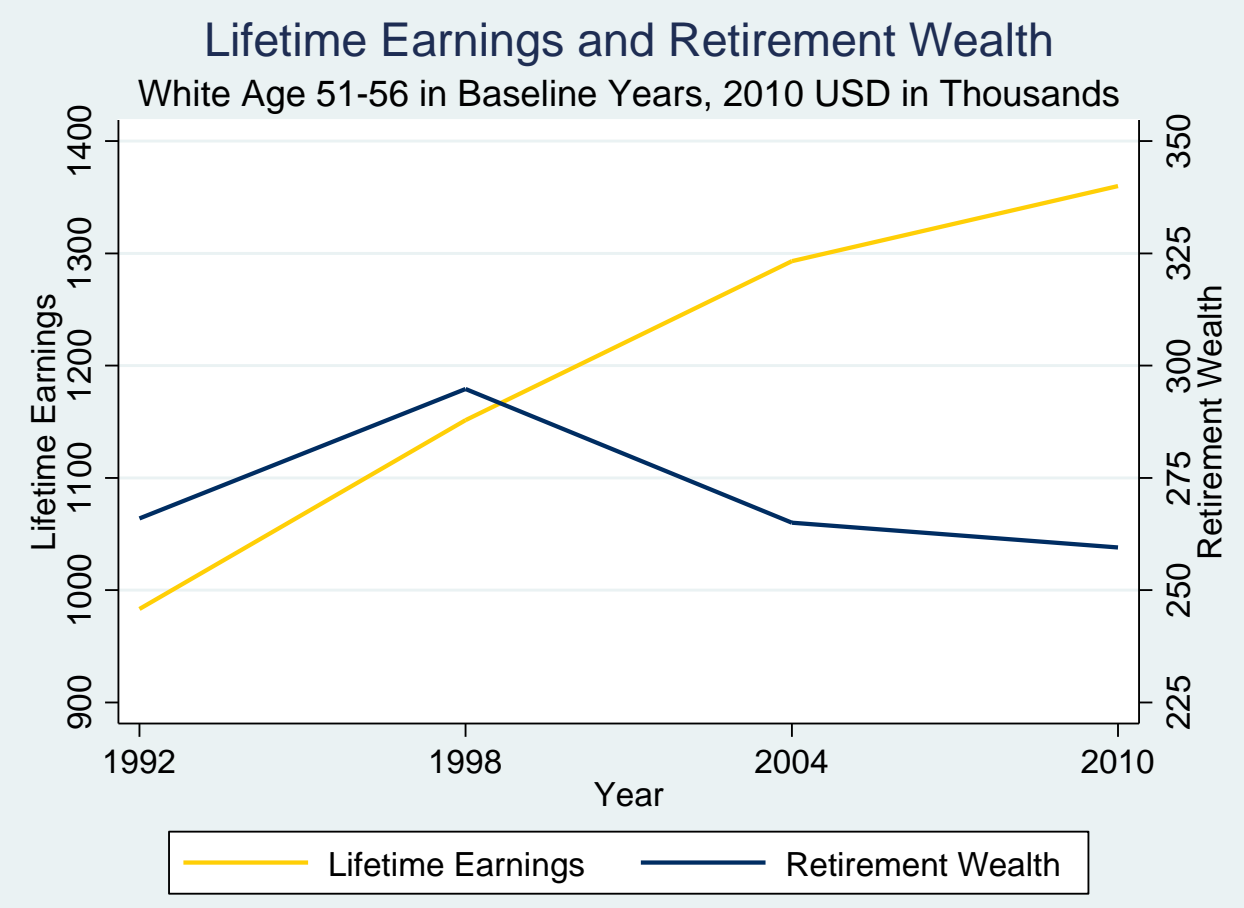

Lifetime Earnings and Retirement Wealth African American Age 51-56 in Baseline Years, 2010 USD in Thousands

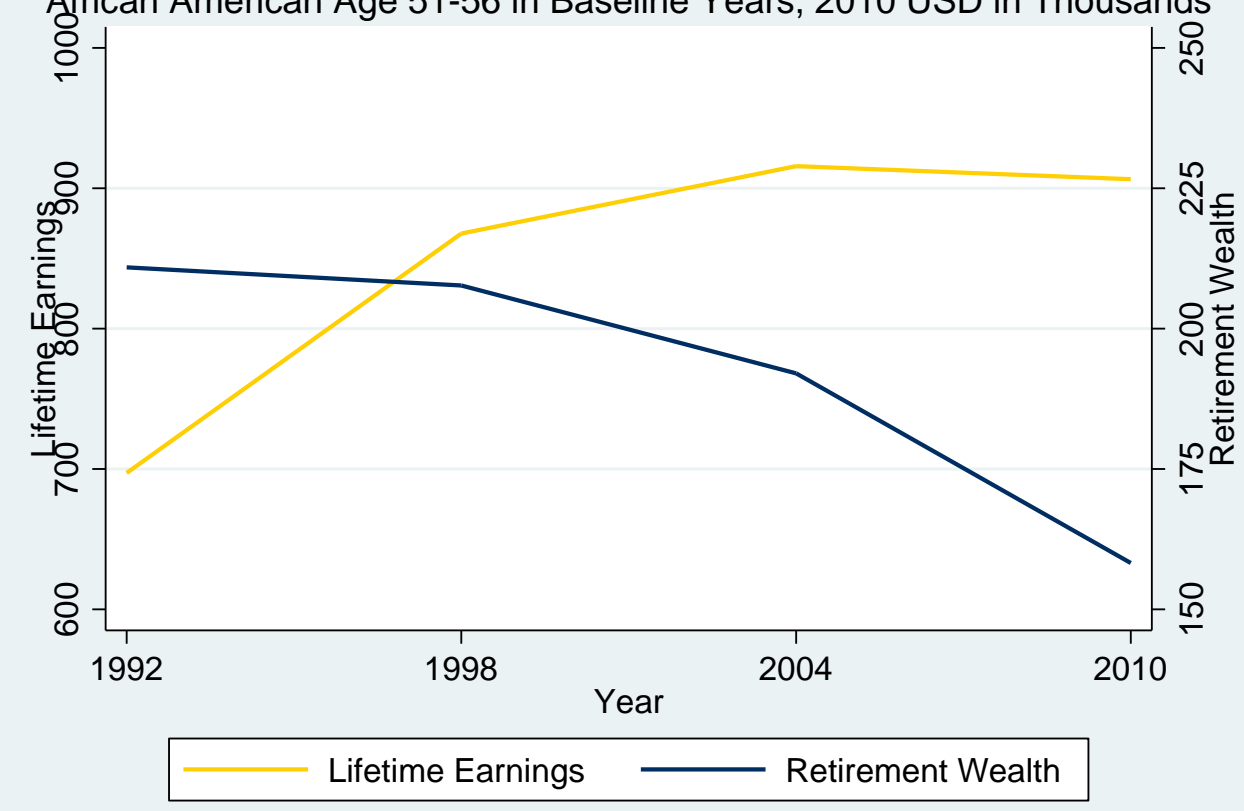


Figure V (Cont.): Cohort Changes in Lifetime Earnings and Retirement Wealth, by Race

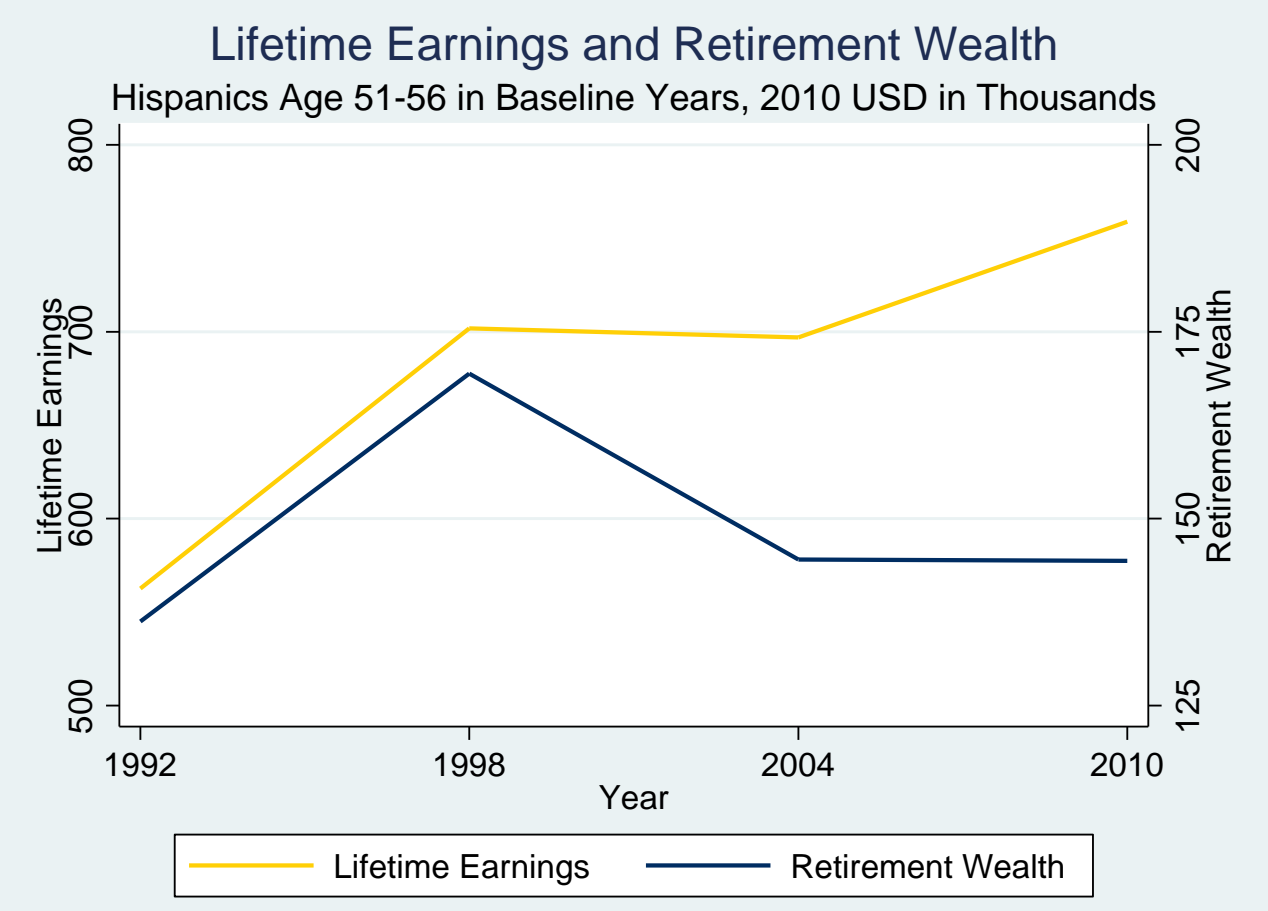


Figure VI: Composition of Retirement Wealth

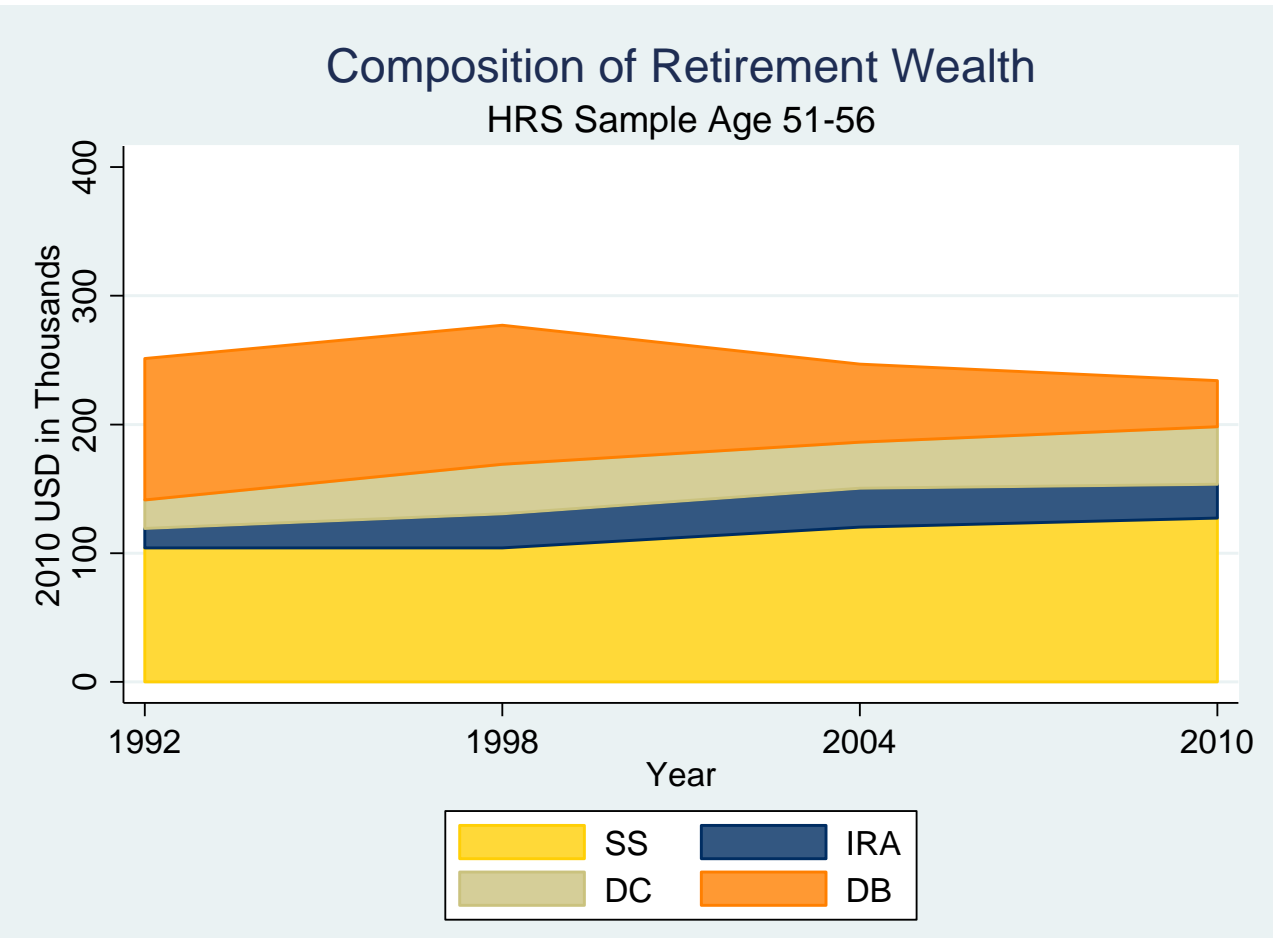


Figure VII: Composition of Retirement Wealth, by Gender
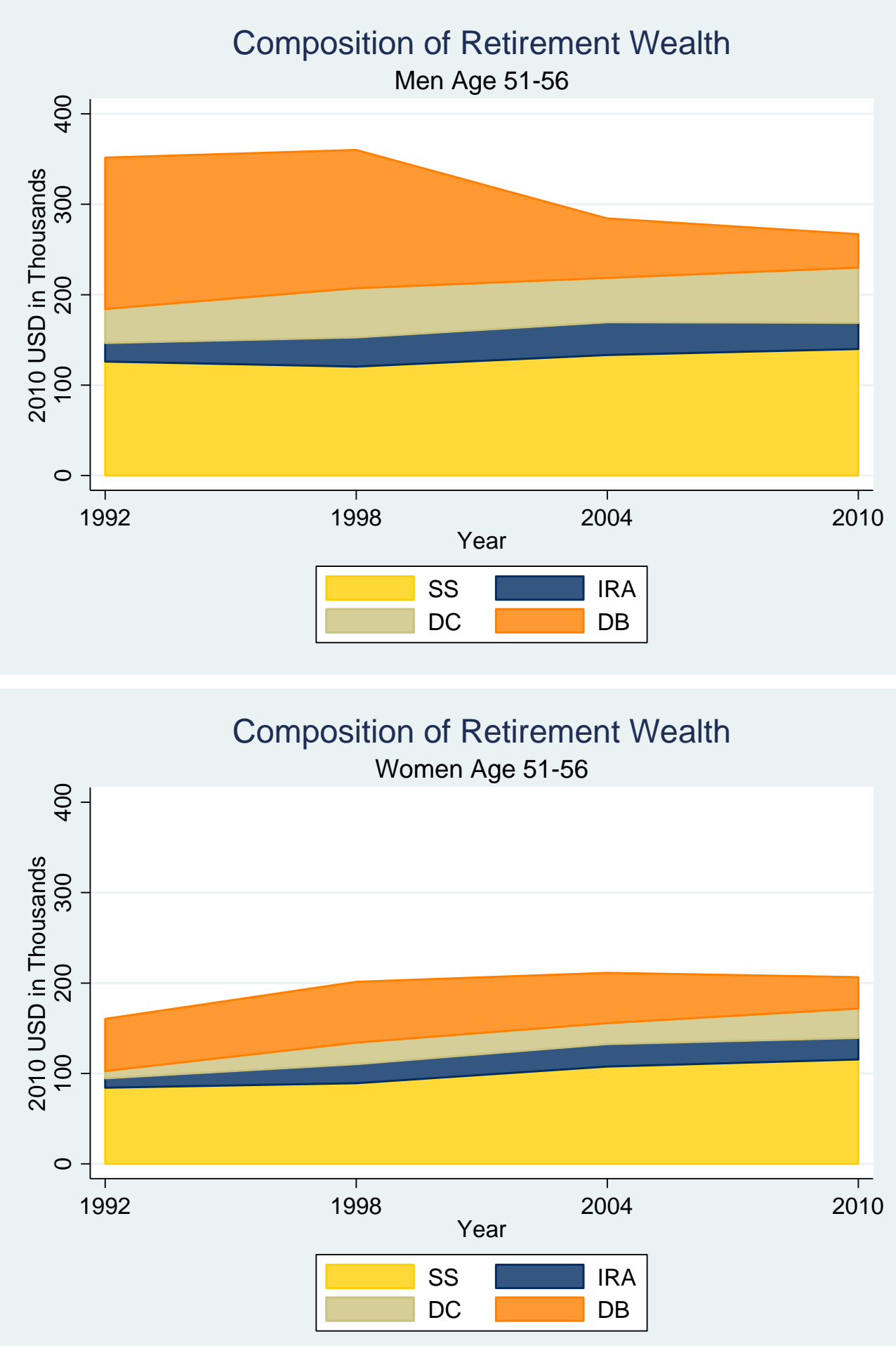
Figure VIII: Composition of Retirement Wealth, by Race

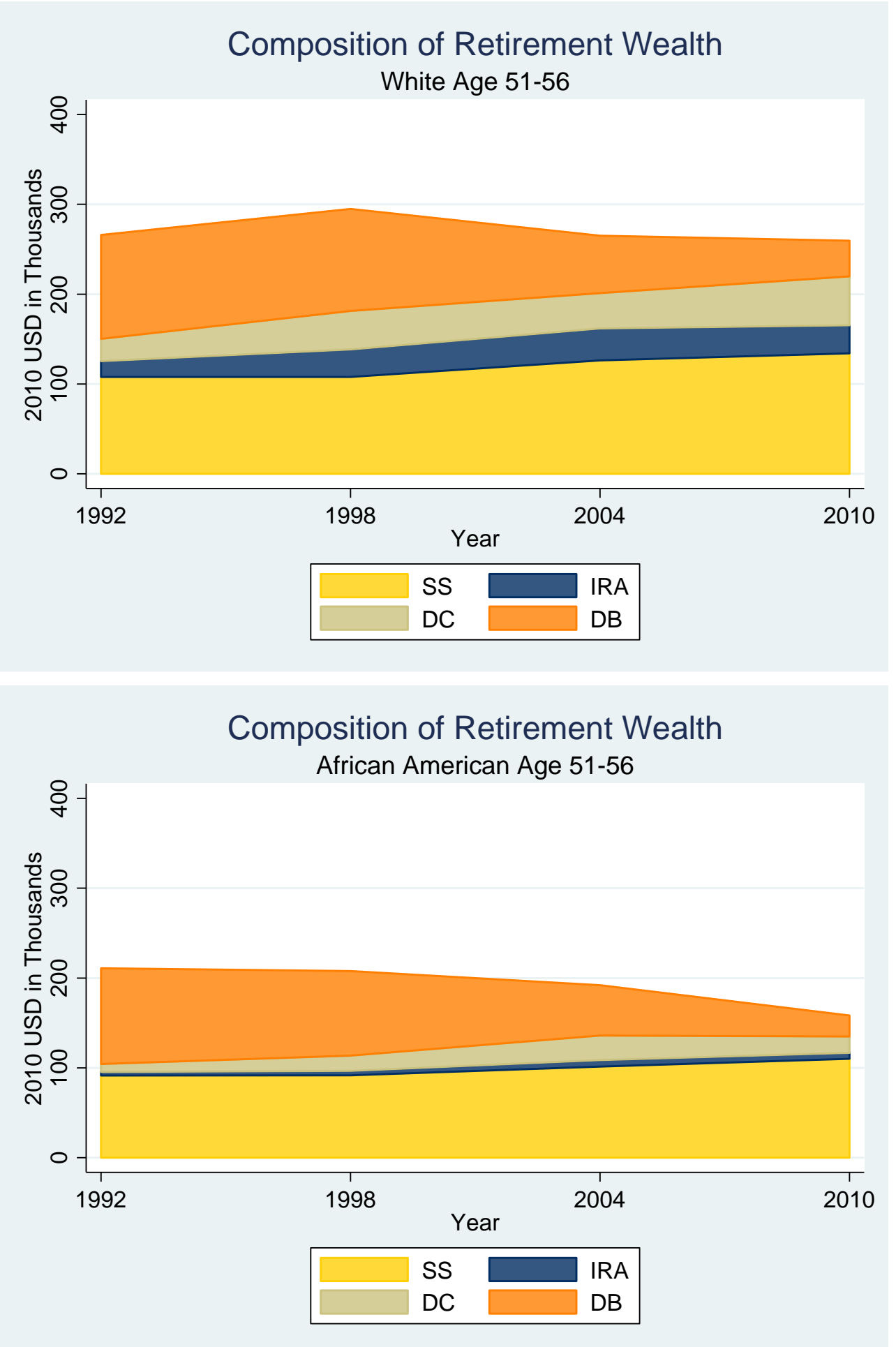


Figure VIII (Cont.): Composition of Retirement Wealth, by Race

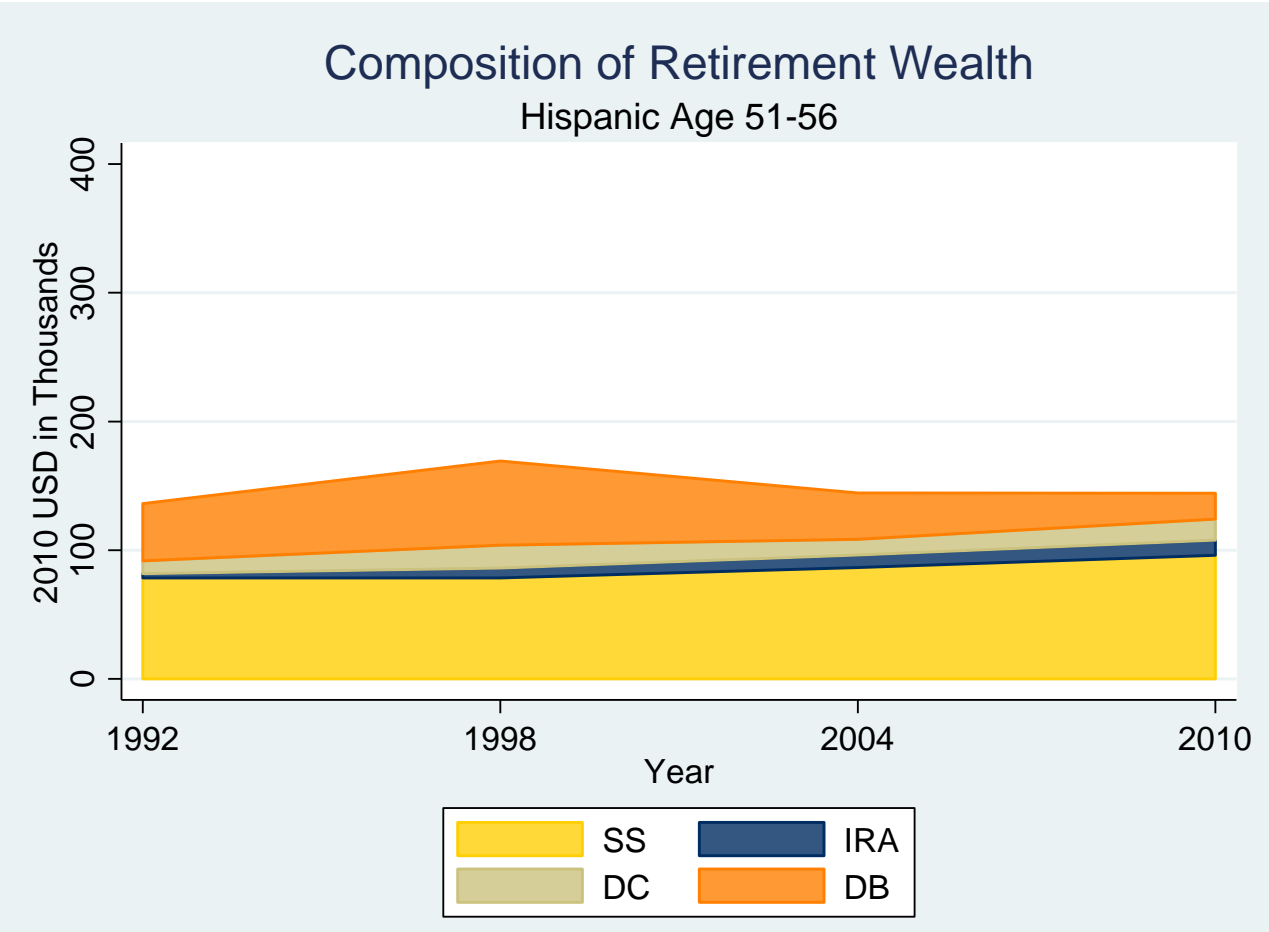


Figure IX: DFL Decomposition
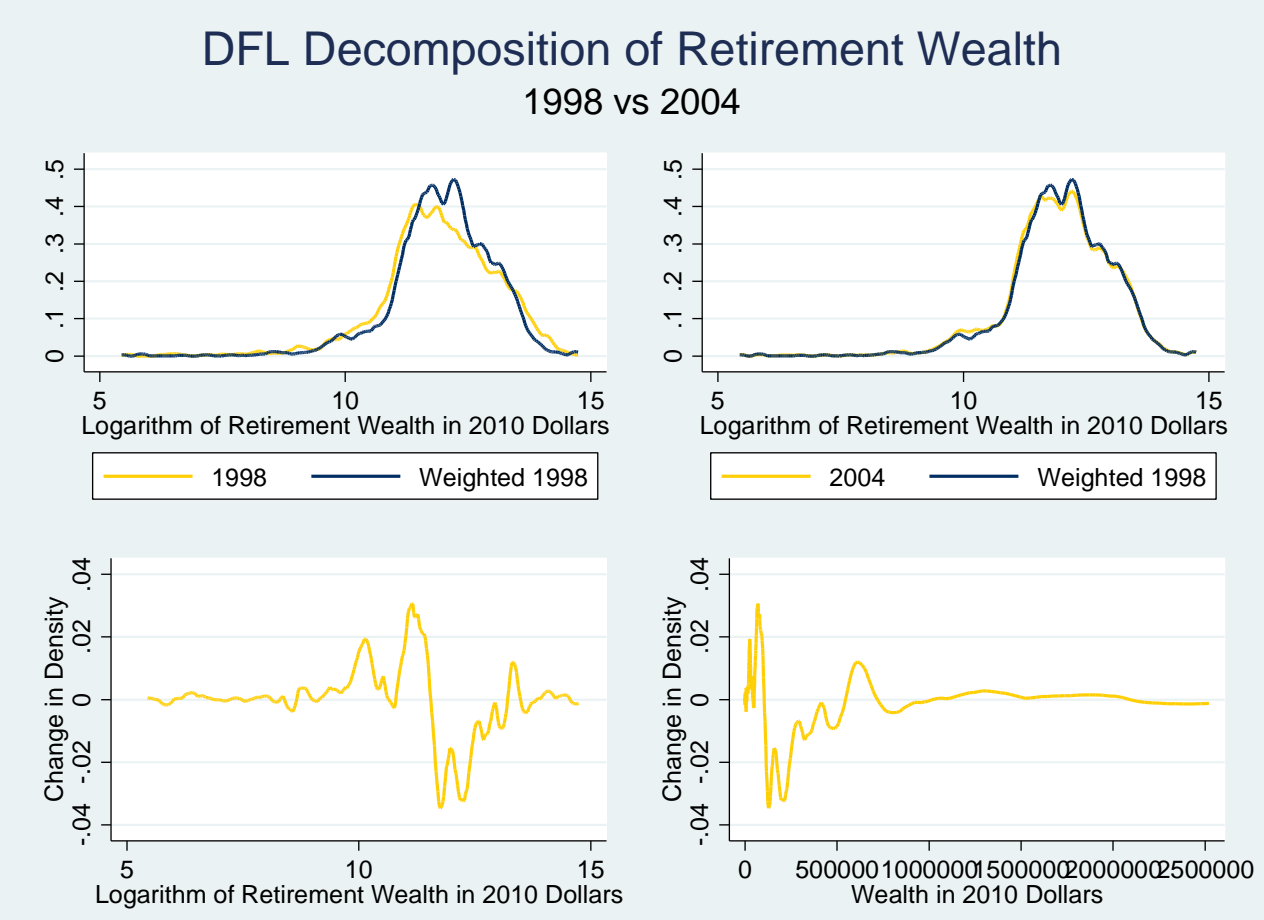

\section{DFL Decomposition of Retirement Wealth 2004 vs 2010}
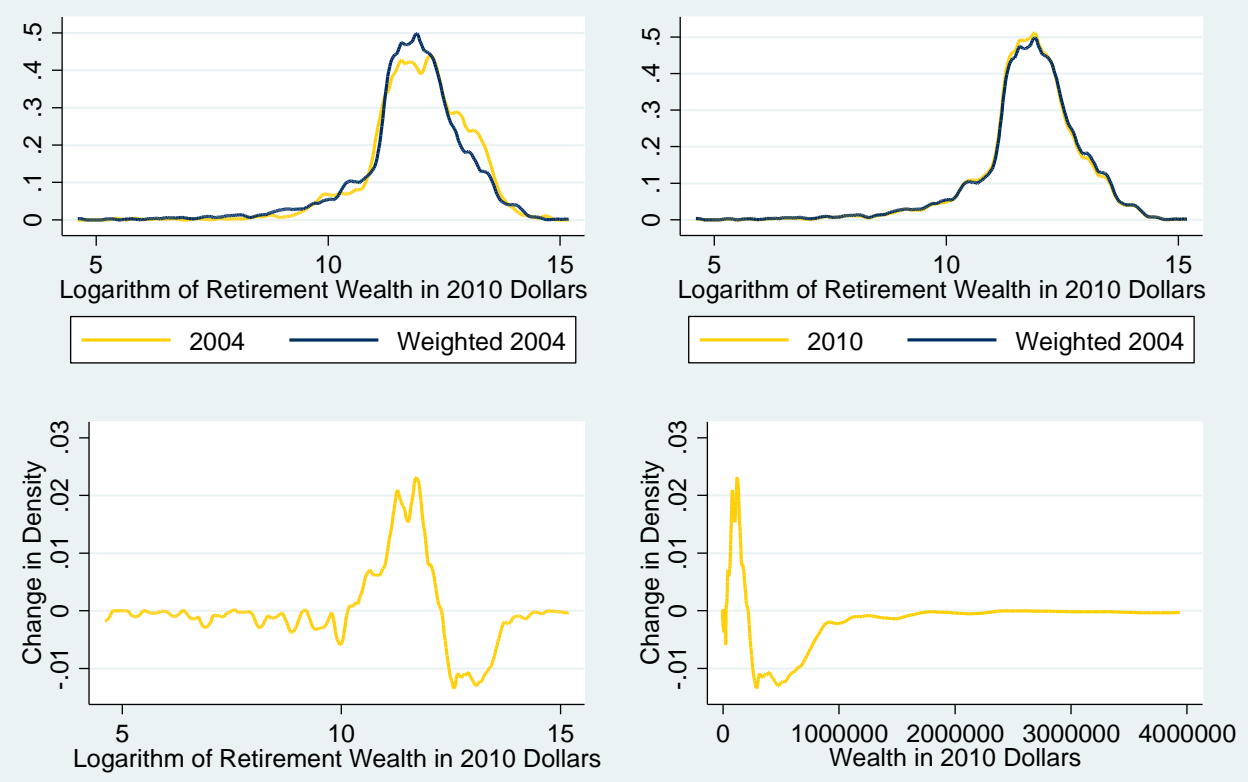


\section{Figure IX (Cont.): DFL Decomposition}

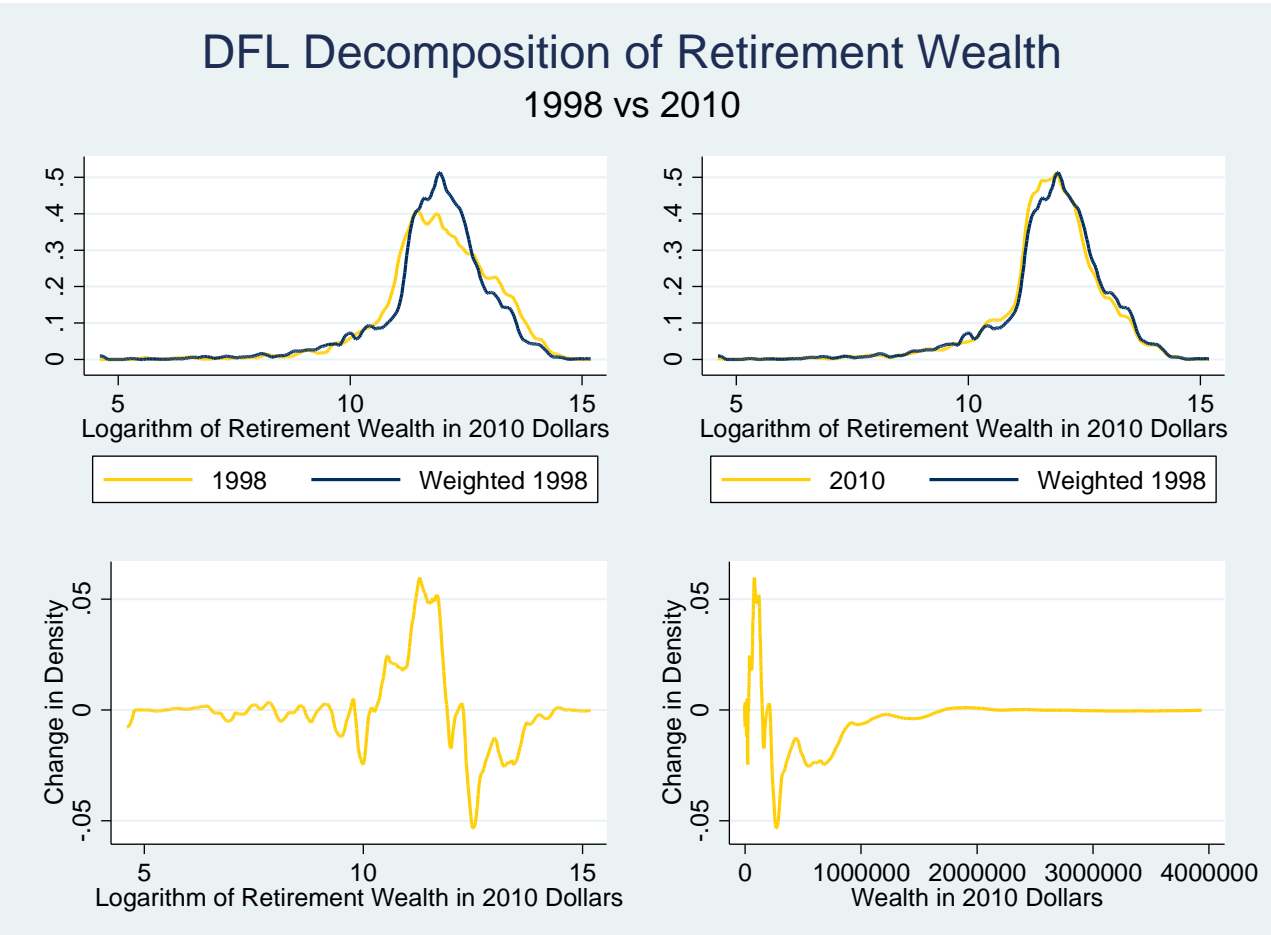


Figure X: Earnings Projection by Level of Education, Projection as of 1997 vs 2003
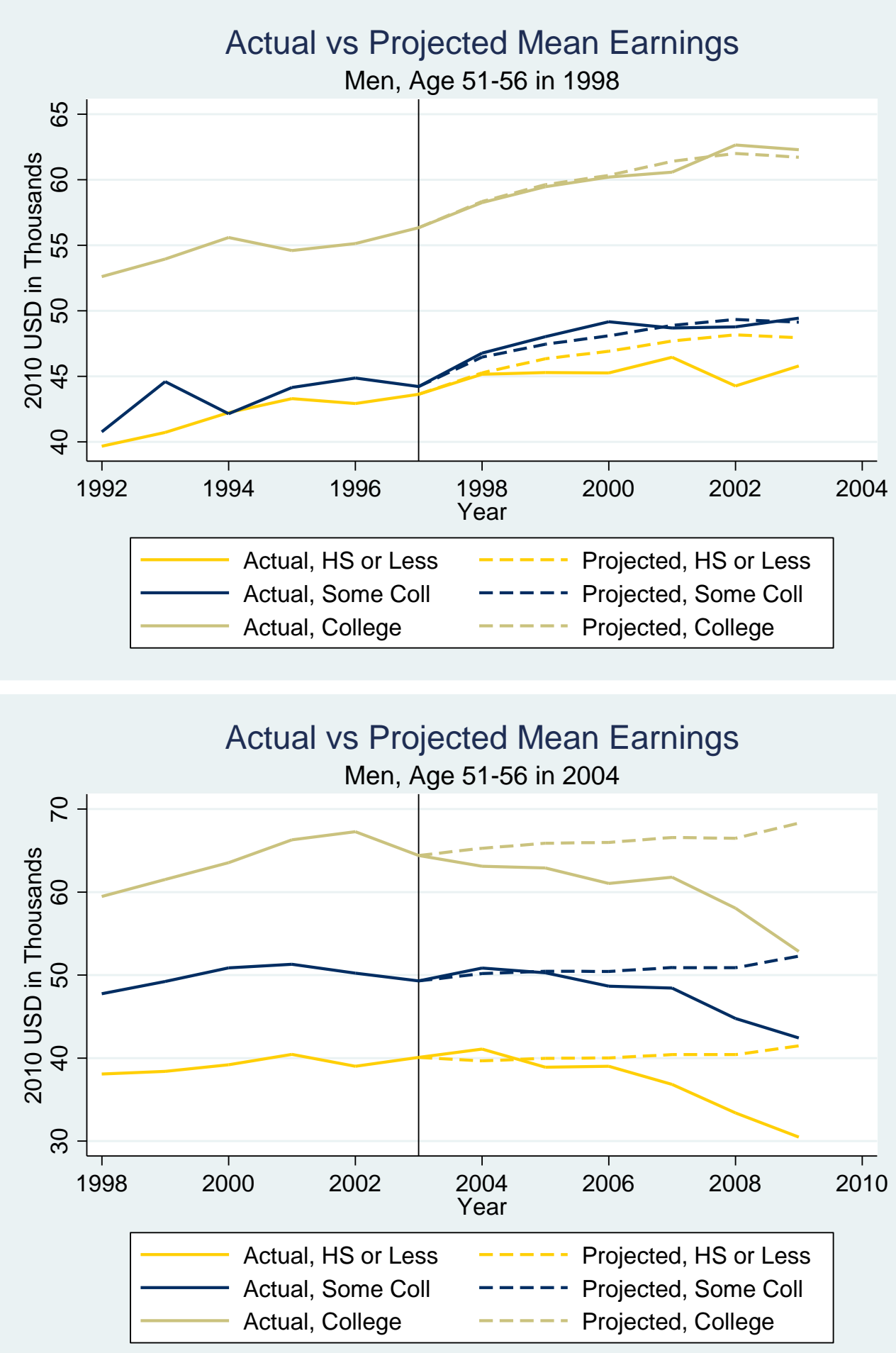
Figure XI: Earnings Projection by Employment and Job Status, Projection as of 1997

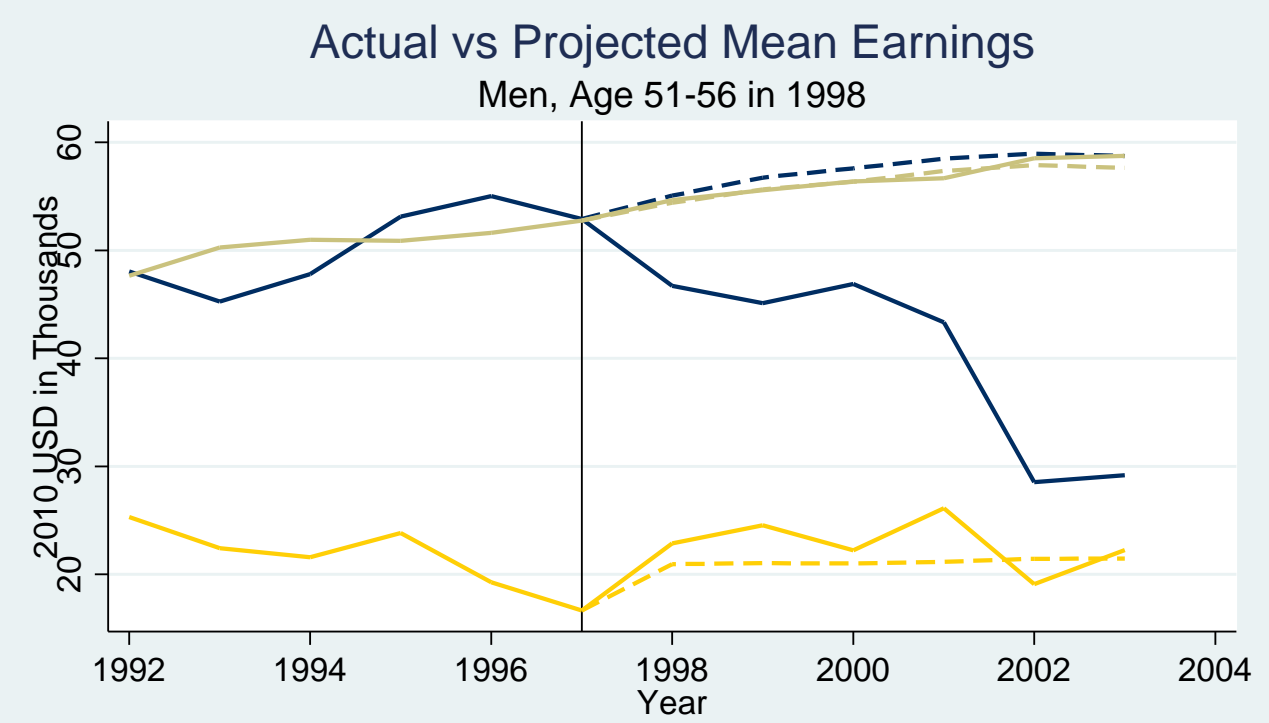

Actual, Not Working in $2004----$ Projected, Not Working in 2004

Actual, Part Time in 2004 - - - - Projected, Part Time in 2004

Actual, Full Time in $2004 \quad----$ Projected, Not Full Time in 2004

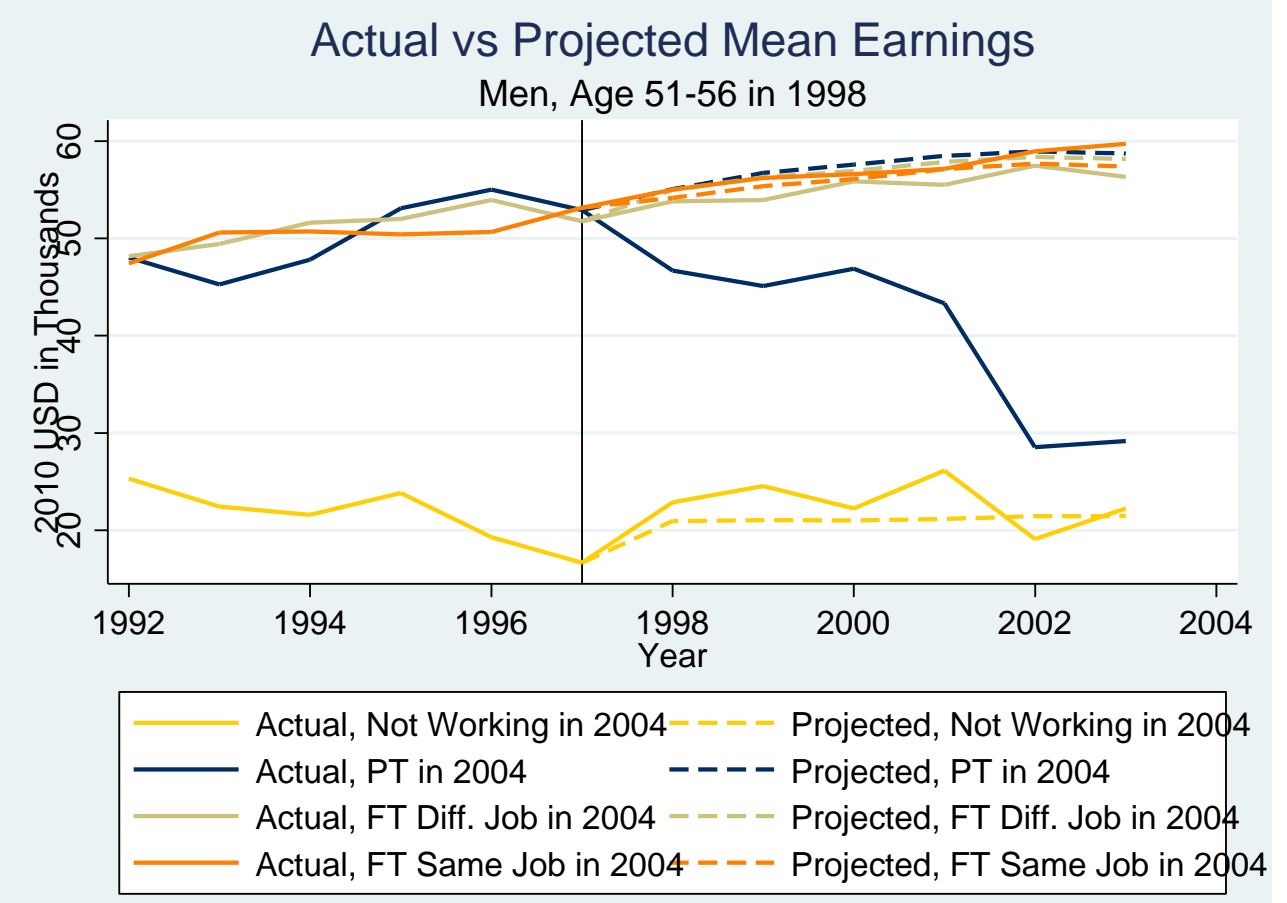


Figure XII: Earnings Projection by Employment and Job Status, Projection as of 2003
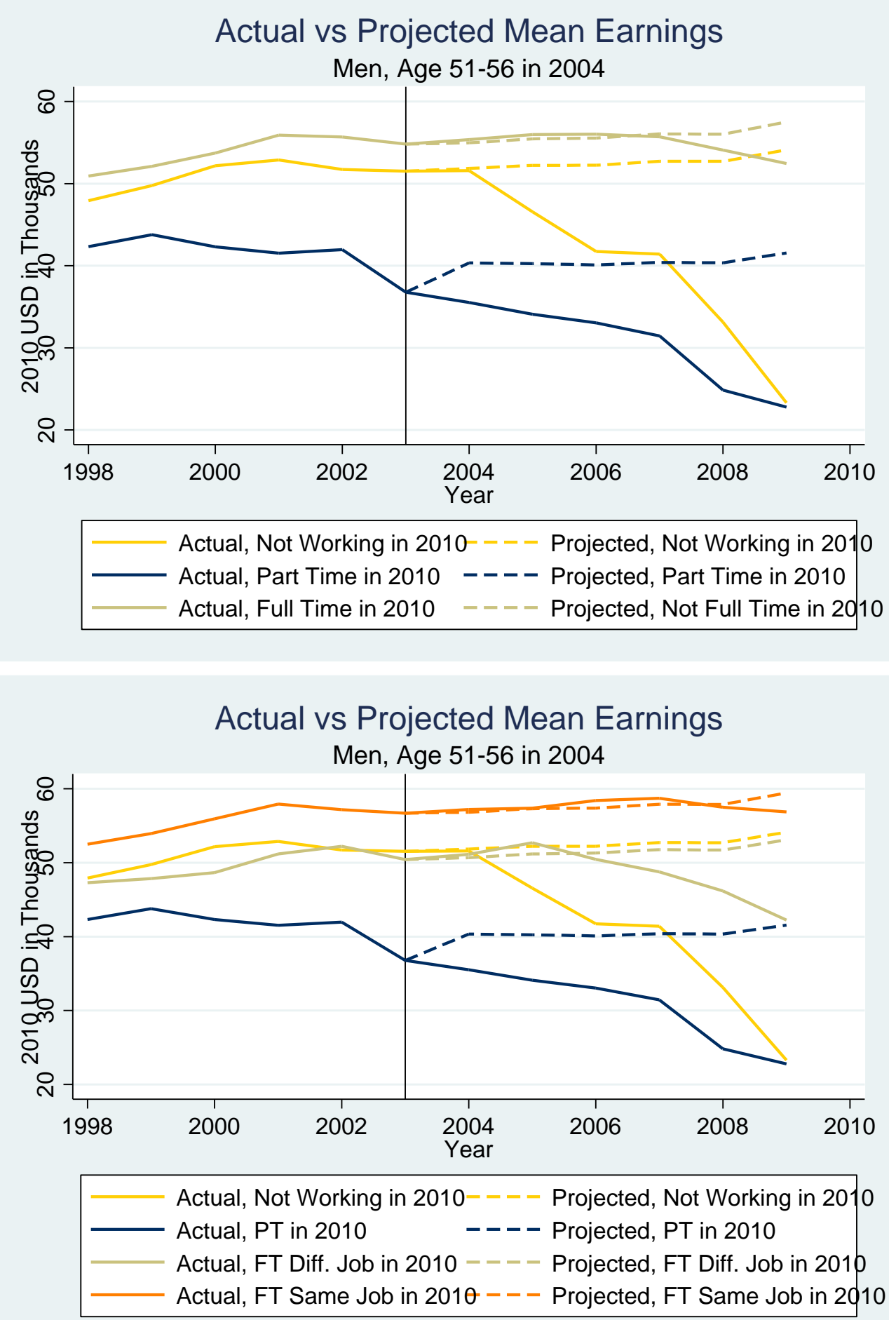
Figure XIII: Earnings Projection in Pension Wealth Estimation

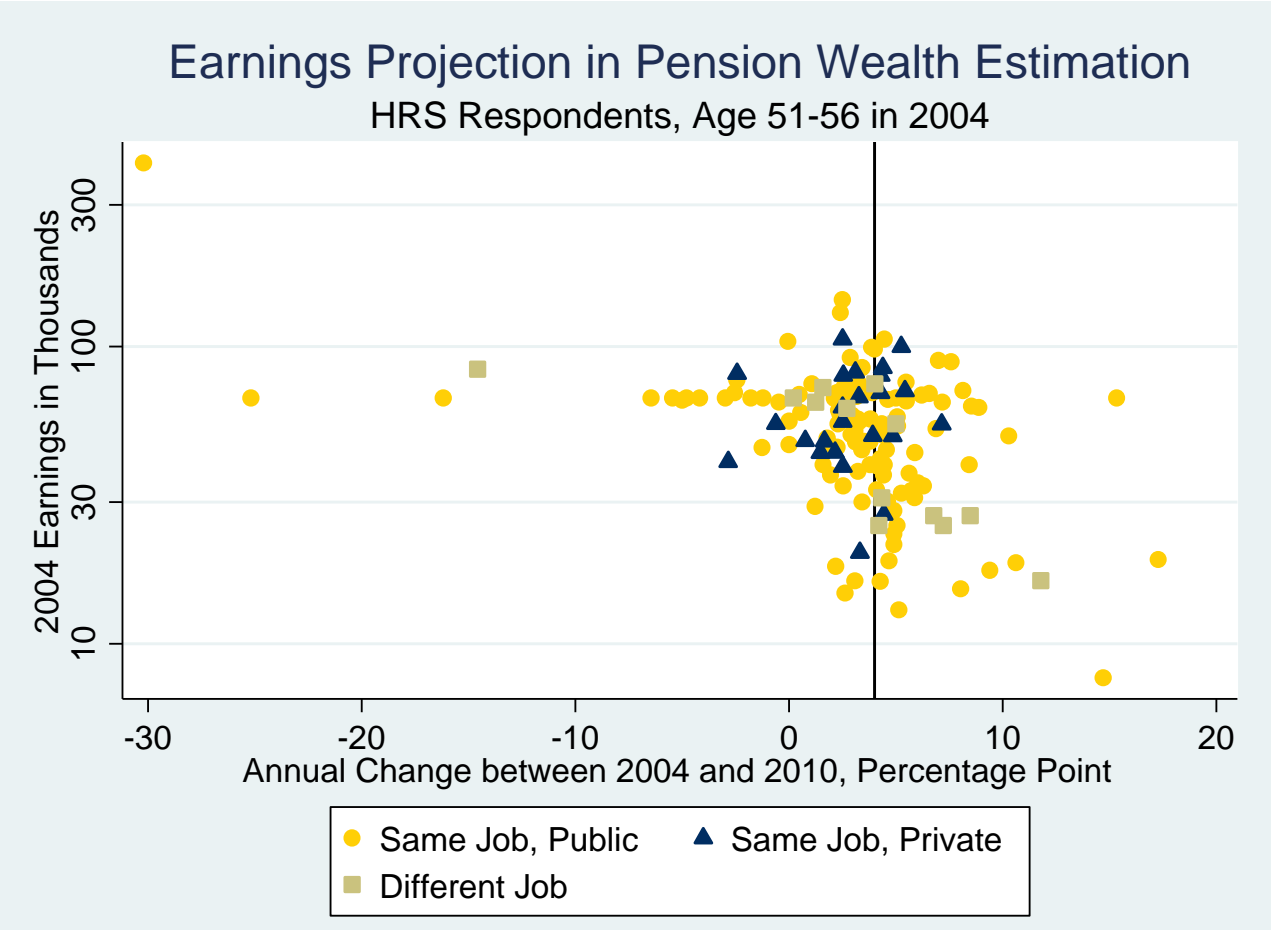

Note: The vertical axis is log-scaled. 
Table I: Components of Full Wealth for Individuals Ages 51-56, by Year (2010 USD)

\begin{tabular}{lllll}
\hline \hline Year & $\mathbf{1 9 9 2}$ & $\mathbf{1 9 9 8}$ & $\mathbf{2 0 0 4}$ & $\mathbf{2 0 1 0}$ \\
\hline Social Security Wealth & $\$ 104,139$ & $\$ 104,154$ & $\$ 120,166$ & $\$ 127,313$ \\
DB & $\$ 109,856$ & $\$ 108,086$ & $\$ 60,549$ & $\$ 35,881$ \\
DC & $\$ 22,152$ & $\$ 38,497$ & $\$ 35,711$ & $\$ 44,675$ \\
IRA & $\$ 15,147$ & $\$ 26,409$ & $\$ 30,395$ & $\$ 26,238$ \\
Other Household Wealth/Assets & $\$ 176,744$ & $\$ 177,530$ & $\$ 217,082$ & $\$ 179,699$ \\
\hline Total & $\$ 428,035$ & $\$ 454,676$ & $\$ 463,903$ & $\$ 413,806$ \\
\hline \hline
\end{tabular}

Note: Numbers are weighted means, in 2010 US Dollars. 
Table II: Donor versus Seeker of DB Plans

\begin{tabular}{lllll}
\hline \hline \multirow{2}{*}{ Self-Report } & \multicolumn{2}{l}{ Employer Plan Description } & \\
& DB Only & DC Only & Both/Combo & Not Matched \\
\hline DB Only & Donor & Seeker & Donor $^{\mathrm{a}}$ & Seeker \\
DC Only & Donor & N/A & Donor $^{\mathrm{a}}$ b & N/A \\
Both/Combo & Donor & Seeker & Donor & Seeker \\
DK Only & Seeker & N/A & Seeker & Seeker \\
\hline \hline
\end{tabular}

a: Only the DB component of the plan is used as a donor plan.

b: The coded plan from project work is used as a donor, but the respondent will not be assigned a DB wealth from this plan. 
Table III: Employer Plan Match Rates by Sector \& Self-Reported Plan Type, 2004 \& 2010

\begin{tabular}{llll}
\hline Sector & Plan Type & $\mathbf{2 0 0 4}$ & $\mathbf{2 0 1 0}$ \\
\hline \multirow{2}{*}{ Private } & All & $31.6 \%$ & $87.9 \%$ \\
& Any DB & $33.6 \%$ & $88.4 \%$ \\
\multirow{2}{*}{ Public } & All & $88.2 \%$ & $96.9 \%$ \\
& Any DB & $92.1 \%$ & $98.3 \%$ \\
\hline \hline
\end{tabular}


Table IV: Comparison between Pension Estimates Based on Coded and Imputed Plans

\begin{tabular}{|c|c|c|c|c|}
\hline & $\begin{array}{l}\text { PV at } 65 \text {, as of } \\
2004\end{array}$ & $\begin{array}{l}\text { PV at } 65 \text {, as of } \\
2010\end{array}$ & $\begin{array}{l}\text { Mean Absolute } \\
\text { Difference }\end{array}$ & Number of Obs. \\
\hline Public, Coded 04 \& 10 & $\$ 242,433$ & $\$ 256,090$ & $\$ 59,997$ & 113 \\
\hline Private, Coded $04 \& 10$ & $\$ 144,224$ & $\$ 177,168$ & $\$ 90,064$ & 24 \\
\hline Private, Coded 10 Only & $\$ 169,527$ & $\$ 115,520$ & $\$ 131,308$ & 51 \\
\hline
\end{tabular}

Note: Numbers are weighted means, in 2010 US Dollars. 
Table V: Pension Wealth on Current Job by Plan Type; Respondent Report Compared to Employer Match, All Workers in HRS 2010 (\$000s)

\begin{tabular}{lllllll}
\hline \hline & DB Wealth & & DC Wealth & \multicolumn{3}{c}{ Total Wealth } \\
$\begin{array}{l}\text { Plan Type } \\
\text { Agreement }\end{array}$ & Respondent & Employer & Respondent & Employer & Respondent & Employer \\
\hline Agree & $\$ 139,964$ & $\$ 139,964$ & $\$ 201,160$ & $\$ 201,160$ & $\$ 341,123$ & $\$ 340,654$ \\
Switch & $\$ 13,698$ & $\$ 14,579$ & $\$ 7,085$ & $\$ 20,437$ & $\$ 20,783$ & $\$ 35,016$ \\
Drop Plan & $\$ 40,468$ & $\$ 28,624$ & $\$ 40,128$ & $\$ 22,565$ & $\$ 80,596$ & $\$ 51,189$ \\
Add Plan & $\$ 69,856$ & $\$ 116,006$ & $\$ 83,706$ & $\$ 140,579$ & $\$ 153,562$ & $\$ 256,585$ \\
\hline Total & $\$ 263,986$ & $\$ 299,173$ & $\$ 332,079$ & $\$ 384,740$ & $\$ 596,065$ & $\$ 683,913$ \\
\hline \hline
\end{tabular}

Note: Numbers are total wealth reported by all HRS respondents with current job pensions in 2010, in 2010 US Dollars. 
Table VI: Additional DC Plans Inferred by Deferred Compensation in W-2 Records (\$000s)

\begin{tabular}{llllll}
\hline \hline $\begin{array}{l}\text { Plan Type } \\
\text { Agreement }\end{array}$ & Respondent & Employer & \% DC in W-2 & Value & Adj. Value \\
\hline \multirow{2}{*}{ Agree } & DB Only & DB Only & $11.7 \%$ & $\$ 1,641$ & $\$ 3,200$ \\
& DC Only & DC Only & $77.3 \%$ & 0 & 0 \\
\multirow{2}{*}{ Type switch } & Both & Both & $73.5 \%$ & 0 & 0 \\
\cline { 2 - 6 } & DB & DC & $54.3 \%$ & 0 & 0 \\
\multirow{2}{*}{ Lose a plan } & Both & DB & $33.8 \%$ & $\$ 10$ & $\$ 20$ \\
\cline { 2 - 6 } Add a plan & Both & DC & $62.5 \%$ & $\$ 5,403$ & $\$ 10,535$ \\
\cline { 2 - 6 } All Others & DB & Both & $80.3 \%$ & 0 & 0 \\
\hline Total & Both & $62.1 \%$ & 0 & 0 \\
\hline \hline
\end{tabular}

Note: Numbers are weighted means, in 2010 US Dollars. 
Table VII: PIA in 2010 USD under Various Earnings Projection Rules, Men

Panel A: 1998 Cohort (Age 51-56 in 1998), Quit Working in the End of 2003

\begin{tabular}{|c|c|c|}
\hline & $\begin{array}{l}\text { Actual through } 1997+ \\
\text { Projected through } 2003\end{array}$ & Actual through 2003 \\
\hline Not Working in 2003 (38) & $\$ 1,210$ & $\$ 1,187$ \\
\hline Working PT in 2003 (16) & $\$ 1,736$ & $\$ 1,772$ \\
\hline $\begin{array}{l}\text { Working FT in 2003, Diff. Job } \\
\text { (53) }\end{array}$ & $\$ 1,617$ & $\$ 1,601$ \\
\hline $\begin{array}{l}\text { Working FT in 2003, Same Job } \\
(122)\end{array}$ & $\$ 1,667$ & $\$ 1,661$ \\
\hline \multicolumn{3}{|c|}{ Panel B: 1998 Cohort (Age 51-56 in 1998), Quit Working at Full Retirement Age } \\
\hline & $\begin{array}{l}\text { Actual through } 1997+ \\
\text { Projected through FRA }\end{array}$ & $\begin{array}{l}\text { Actual through } 2003+ \\
\text { Projected through FRA }\end{array}$ \\
\hline Not Working in $2003(38)$ & $\$ 1,463$ & $\$ 1,491$ \\
\hline Working PT in 2003 (16) & $\$ 1,534$ & $\$ 1,530$ \\
\hline $\begin{array}{l}\text { Working FT in 2003, Diff. Job } \\
\text { (53) }\end{array}$ & $\$ 1,718$ & $\$ 1.699$ \\
\hline $\begin{array}{l}\text { Working FT in 2003, Same Job } \\
(122)\end{array}$ & $\$ 1,778$ & $\$ 1,789$ \\
\hline \multicolumn{3}{|c|}{ Panel C: 2004 Cohort (Age 51-56 in 2004), Quit Working in the End of 2009} \\
\hline & $\begin{array}{l}\text { Actual through } 2003+ \\
\text { Projected through } 2009\end{array}$ & Actual through 2009 \\
\hline Not Working in $2009(165)$ & $\$ 1,572$ & $\$ 1,545$ \\
\hline Working PT in 2009 (33) & $\$ 1,417$ & $\$ 1,399$ \\
\hline $\begin{array}{l}\text { Working FT in 2009, Diff. Job } \\
\text { (112) }\end{array}$ & $\$ 1,601$ & $\$ 1,598$ \\
\hline $\begin{array}{l}\text { Working FT in 2009, Same Job } \\
\text { (251) }\end{array}$ & $\$ 1,686$ & $\$ 1,689$ \\
\hline
\end{tabular}




\begin{tabular}{|c|c|c|}
\hline \multicolumn{3}{|c|}{ Panel D: 2004 Cohort (Age 51-56 in 2004), Quit Working at Full Retirement Age } \\
\hline & Actual through $2003+$ & Actual through $2009+$ \\
\hline & Projected through FRA & Projected through FRA \\
\hline Not Working in 2009 (165) & $\$ 1,657$ & $\$ 1,574$ \\
\hline Working PT in 2009 (33) & $\$ 1,420$ & $\$ 1,393$ \\
\hline $\begin{array}{l}\text { Working FT in 2009, Diff. Job } \\
\text { (112) }\end{array}$ & $\$ 1,639$ & $\$ 1,634$ \\
\hline $\begin{array}{l}\text { Working FT in 2009, Same Job } \\
(251)\end{array}$ & $\$ 1,714$ & $\$ 1,718$ \\
\hline
\end{tabular}

Notes: Numbers are weighted means, in 2010 US Dollars. Sample size is in the parenthesis in the first column of each row. 
Table VIII: PIA in 2010 USD under Various Earnings Projection Rules, Women

Panel A: 1998 Cohort (Age 51-56 in 1998), Quit Working in the End of 2003

\begin{tabular}{|c|c|c|}
\hline & $\begin{array}{l}\text { Actual through } 1997+ \\
\text { Projected through } 2003\end{array}$ & Actual through 2003 \\
\hline Not Working in $2003(94)$ & $\$ 463$ & $\$ 453$ \\
\hline Working PT in 2003 (56) & $\$ 736$ & $\$ 742$ \\
\hline $\begin{array}{l}\text { Working FT in 2003, Diff. Job } \\
\text { (66) }\end{array}$ & $\$ 1,279$ & $\$ 1,299$ \\
\hline $\begin{array}{l}\text { Working FT in 2003, Same Job } \\
\text { (119) }\end{array}$ & $\$ 1,217$ & $\$ 1,230$ \\
\hline \multicolumn{3}{|c|}{ Panel B: 1998 Cohort (Age 51-56 in 1998), Quit Working at Full Retirement Age } \\
\hline & $\begin{array}{l}\text { Actual through } 1997+ \\
\text { Projected through FRA }\end{array}$ & $\begin{array}{l}\text { Actual through } 2003+ \\
\text { Projected through FRA }\end{array}$ \\
\hline Not Working in $2003(94)$ & $\$ 790$ & $\$ 728$ \\
\hline Working PT in 2003 (56) & $\$ 956$ & $\$ 941$ \\
\hline $\begin{array}{l}\text { Working FT in 2003, Diff. Job } \\
\text { (66) }\end{array}$ & $\$ 1,144$ & $\$ 1,190$ \\
\hline $\begin{array}{l}\text { Working FT in 2003, Same Job } \\
\text { (119) }\end{array}$ & $\$ 1,346$ & $\$ 1,375$ \\
\hline \multicolumn{3}{|c|}{ Panel C: 2004 Cohort (Age 51-56 in 2004), Quit Working in the End of 2009} \\
\hline & $\begin{array}{l}\text { Actual through } 2003+ \\
\text { Projected through } 2009\end{array}$ & Actual through 2009 \\
\hline Not Working in $2009(186)$ & $\$ 1,023$ & $\$ 995$ \\
\hline Working PT in 2009 (104) & $\$ 1,021$ & $\$ 1,004$ \\
\hline $\begin{array}{l}\text { Working FT in 2009, Diff. Job } \\
\text { (95) }\end{array}$ & $\$ 1,214$ & $\$ 1,213$ \\
\hline $\begin{array}{l}\text { Working FT in 2009, Same Job } \\
\text { (238) }\end{array}$ & $\$ 1,245$ & $\$ 1,256$ \\
\hline
\end{tabular}




\begin{tabular}{|c|c|c|}
\hline \multicolumn{3}{|c|}{ Panel D: 2004 Cohort (Age 51-56 in 2004), Quit Working at Full Retirement Age } \\
\hline & Actual through $2003+$ & Actual through $2009+$ \\
\hline & Projected through FRA & Projected through FRA \\
\hline Not Working in 2009 (186) & $\$ 1,083$ & $\$ 980$ \\
\hline Working PT in 2009 (104) & $\$ 1,079$ & $\$ 1,040$ \\
\hline $\begin{array}{l}\text { Working FT in 2009, Diff. Job } \\
\text { (95) }\end{array}$ & $\$ 1,294$ & $\$ 1,296$ \\
\hline $\begin{array}{l}\text { Working FT in 2009, Same Job } \\
\text { (238) }\end{array}$ & $\$ 1,325$ & $\$ 1,346$ \\
\hline
\end{tabular}

Notes: Numbers are weighted means, in 2010 US Dollars. Sample size is in the parenthesis in the first column of each row. 
Table IX: Earning Projection Used in Pension Wealth Estimation

\begin{tabular}{|c|c|c|c|}
\hline \multicolumn{4}{|c|}{ Panel A: Men, Age 51-56 in 2004, Plan Coded in 2004} \\
\hline & Actual 2004 Earnings & Projected 2010 Earnings & Actual 2010 Earnings \\
\hline Same Employer, Public (43) & $\$ 73,565$ & $\$ 80,704$ & $\$ 74,005$ \\
\hline Same Employer, Private (15) & $\$ 73,747$ & $\$ 80,903$ & $\$ 76,327$ \\
\hline Different Employer, w/ Pension in 2010 Job (6) & $\$ 59,148$ & $\$ 64,887$ & $\$ 51,075$ \\
\hline Different Employer, No Pension in 2010 Job (27) & $\$ 73,698$ & $\$ 80,850$ & $\$ 41,673$ \\
\hline Not Working in 2010 (32) & $\$ 76,742$ & $\$ 84,819$ & - \\
\hline \multicolumn{4}{|c|}{ Panel B: Women, Age 51-56 in 2004, Plan Coded in 2004} \\
\hline & Actual 2004 Earnings & Projected 2010 Earnings & Actual 2010 Earnings \\
\hline Same Employer, Public (70) & $\$ 69,159$ & $\$ 75,870$ & $\$ 65,681$ \\
\hline Same Employer, Private (9) & $\$ 69,569$ & $\$ 76,319$ & $\$ 73,076$ \\
\hline Different Employer, w/ Pension in 2010 Job (7) & $\$ 58,165$ & $\$ 63,809$ & $\$ 57,266$ \\
\hline Different Employer, No Pension in 2010 Job (27) & $\$ 60,579$ & $\$ 66,019$ & $\$ 20,536$ \\
\hline Not Working in 2010 (55) & $\$ 59,545$ & $\$ 65,323$ & - \\
\hline
\end{tabular}

Notes: Numbers are weighted means, in 2010 US Dollars. Sample size is in the parenthesis in the first column of each row. 
Table X: Estimated Pension Wealth at Age 65

\begin{tabular}{|c|c|c|c|c|}
\hline \multicolumn{5}{|c|}{ Panel A: Men, Age 51-56 in 2004, Plan Coded in 2004} \\
\hline & \multirow{2}{*}{$\begin{array}{l}\text { Wealth in } 2004 \\
\underline{2004 \mathrm{Job}}\end{array}$} & \multicolumn{2}{|c|}{ Wealth in 2010} & \multirow[t]{2}{*}{ Difference } \\
\hline & & $\underline{2004 \text { Job }}$ & $2010 \mathrm{Job}$ & \\
\hline Same Employer, Public (43) & $\$ 383,880$ & - & $\$ 318,907$ & $(\$ 64,943)$ \\
\hline Same Employer, Private (15) & $\$ 209,469$ & - & $\$ 242,438$ & $\$ 32,969$ \\
\hline Different Employer, w/ Pension in 2010 Job (6) & $\$ 274,614$ & $\$ 277,631$ & $\$ 49,026$ & $\$ 52,301$ \\
\hline Different Employer, No Pension in 2010 Job (27) & $\$ 349,872$ & $\$ 259,038$ & - & $(\$ 90,834)$ \\
\hline Not Working in 2010 (32) & $\$ 398,643$ & $\$ 401,962$ & - & $\$ 7,098$ \\
\hline \multicolumn{5}{|c|}{ Panel B: Women, Age 51-56 in 2004, Plan Coded in 2004} \\
\hline & Wealth in 2004 & Wealth in & & Difference \\
\hline & $\underline{2004}$ Job & $\underline{2004}$ Job & $\underline{2010 \mathrm{Job}}$ & \\
\hline Same Employer, Public (70) & $\$ 363,648$ & - & $\$ 337,585$ & $(\$ 26,063)$ \\
\hline Same Employer, Private (9) & $\$ 125,651$ & - & $\$ 209,880$ & $\$ 84,229$ \\
\hline Different Employer, w/ Pension in 2010 Job (7) & $\$ 220,628$ & $\$ 48,644$ & $\$ 73,045$ & $(\$ 98,938)$ \\
\hline Different Employer, No Pension in 2010 Job (27) & $\$ 362,616$ & $\$ 238,163$ & - & $(\$ 124,453)$ \\
\hline Not Working in 2010 (55) & $\$ 368,993$ & $\$ 329,582$ & - & $(\$ 39,411)$ \\
\hline
\end{tabular}

Note: Numbers are weighted means, in 2010 US Dollars. Sample size is in the parenthesis in the first column of each row. 
Table XI: Estimated Pension Wealth at Expected Retirement Age

\begin{tabular}{|c|c|c|c|c|}
\hline \multicolumn{5}{|c|}{ Panel A: Men, Age 51-56 in 2004, Plan Coded in 2004} \\
\hline & Wealth in 2004 & Wealth in & & Difference \\
\hline & $\underline{2004 \text { Job }}$ & $\underline{2004 \text { Job }}$ & $\underline{2010 ~ J o b}$ & \\
\hline Same Employer, Public (43) & $\$ 364,624$ & - & $\$ 334,469$ & $(\$ 30,155)$ \\
\hline Same Employer, Private (15) & $\$ 210,893$ & - & $\$ 254,469$ & $\$ 43,576$ \\
\hline Different Employer, w/ Pension in 2010 Job (6) & $\$ 295,171$ & $\$ 277,631$ & $\$ 63,093$ & $\$ 45,553$ \\
\hline Different Employer, No Pension in 2010 Job (27) & $\$ 344,196$ & $\$ 259,038$ & - & $(\$ 85,128)$ \\
\hline Not Working in 2010 (32) & $\$ 420,443$ & $\$ 401,962$ & - & $(\$ 18,481)$ \\
\hline \multicolumn{5}{|c|}{ Panel B: Women, Age 51-56 in 2004, Plan Coded in 2004} \\
\hline & Wealth in 2004 & Wealth in & & Difference \\
\hline & $\underline{2004 \mathrm{Job}}$ & $\underline{2004 ~ J o b}$ & $\underline{2010 ~ J o b}$ & \\
\hline Same Employer, Public (70) & $\$ 351,935$ & - & $\$ 340,257$ & $(\$ 11,678)$ \\
\hline Same Employer, Private (9) & $\$ 122,701$ & - & $\$ 203,605$ & $\$ 80,964$ \\
\hline Different Employer, w/ Pension in 2010 Job (7) & $\$ 223,235$ & $\$ 48,644$ & $\$ 61,249$ & $(\$ 113,340)$ \\
\hline Different Employer , No Pension in 2010 Job (27) & $\$ 356,340$ & $\$ 238,163$ & - & $(\$ 118,177)$ \\
\hline Not Working in 2010 (55) & $\$ 334,286$ & $\$ 329,582$ & - & $(\$ 4,074)$ \\
\hline
\end{tabular}

Note: Numbers are weighted means, in 2010 US Dollars. Sample size is in the parenthesis in the first column of each row. 


\section{Appendix Table I: Indexed Lifetime Earnings (2010 USD)}

\begin{tabular}{lllll}
\hline \hline & & \multicolumn{4}{c}{ Year Cohort Ages 51-56 } \\
& $\mathbf{1 9 9 2}$ & $\mathbf{1 9 9 8}$ & $\mathbf{2 0 0 4}$ & $\mathbf{2 0 1 0}$ \\
\hline Decile of Lifetime Earnings & & & & \\
$\mathbf{1}$ & $\$ 27,126$ & $\$ 51,191$ & $\$ 81,900$ & $\$ 111,963$ \\
$\mathbf{2}$ & $\$ 131,911$ & $\$ 223,320$ & $\$ 272,480$ & $\$ 315,819$ \\
$\mathbf{3}$ & $\$ 264,237$ & $\$ 412,699$ & $\$ 453,603$ & $\$ 490,714$ \\
$\mathbf{4}$ & $\$ 437,322$ & $\$ 627,088$ & $\$ 650,849$ & $\$ 680,506$ \\
$\mathbf{5}$ & $\$ 628,228$ & $\$ 842,168$ & $\$ 864,946$ & $\$ 867,344$ \\
$\mathbf{6}$ & $\$ 858,985$ & $\$ 1,057,339$ & $\$ 1,100,897$ & $\$ 1,091,817$ \\
$\mathbf{7}$ & $\$ 1,108,439$ & $\$ 1,308,172$ & $\$ 1,373,018$ & $\$ 1,344,237$ \\
$\mathbf{8}$ & $\$ 1,398,342$ & $\$ 1,616,077$ & $\$ 1,723,779$ & $\$ 1,685,097$ \\
$\mathbf{9}$ & $\$ 1,715,082$ & $\$ 1,964,248$ & $\$ 2,166,316$ & $\$ 2,147,036$ \\
$\mathbf{1 0}$ & $\$ 2,683,359$ & $\$ 2,814,238$ & $\$ 3,333,826$ & $\$ 3,701,822$ \\
$\mathbf{1 - 5}$ & $\$ 297,765$ & $\$ 431,293$ & $\$ 464,755$ & $\$ 493,269$ \\
$\mathbf{6 - 1 0}$ & $\$ 1,552,841$ & $\$ 1,752,015$ & $\$ 1,939,567$ & $\$ 1,994,002$ \\
\hline White & $\$ 983,212$ & $\$ 1,151,508$ & $\$ 1,293,106$ & $\$ 1,359,806$ \\
African American & $\$ 697,260$ & $\$ 867,759$ & $\$ 915,770$ & $\$ 906,447$ \\
Hispanic & $\$ 562,662$ & $\$ 701,851$ & $\$ 696,934$ & $\$ 758,934$ \\
\hline Male & $\$ 1,431,242$ & $\$ 1,561,473$ & $\$ 1,627,345$ & $\$ 1,544,128$ \\
Female & $\$ 465,973$ & $\$ 660,840$ & $\$ 797,028$ & $\$ 964,051$ \\
\hline All & $\$ 924,895$ & $\$ 1,091,014$ & $\$ 1,201,307$ & $\$ 1,242,987$ \\
No. of Observations & 5,579 & 3,078 & 3,368 & 4,780 \\
\hline \hline & & & & \\
\hline
\end{tabular}

Notes: Lifetime earnings up to date of cohort entry into HRS are indexed on the Social Security wage index up to that date of cohort entry. They are then converted to 2010 USD using CPI. 


\section{Appendix Table II: Social Security Wealth (2010 USD)}

\begin{tabular}{lllll}
\hline \hline & & \multicolumn{3}{c}{ Year Cohort Ages 51-56 } \\
& $\mathbf{1 9 9 2}$ & $\mathbf{1 9 9 8}$ & $\mathbf{2 0 0 4}$ & $\mathbf{2 0 1 0}$ \\
\hline Decile of Lifetime Earnings & & & & \\
$\mathbf{1}$ & $\$ 31,083$ & $\$ 34,182$ & $\$ 44,321$ & $\$ 32,756$ \\
$\mathbf{2}$ & $\$ 43,046$ & $\$ 55,644$ & $\$ 65,820$ & $\$ 67,835$ \\
$\mathbf{3}$ & $\$ 65,836$ & $\$ 74,690$ & $\$ 84,286$ & $\$ 85,718$ \\
$\mathbf{4}$ & $\$ 86,207$ & $\$ 91,305$ & $\$ 100,620$ & $\$ 99,144$ \\
$\mathbf{5}$ & $\$ 101,538$ & $\$ 102,739$ & $\$ 114,361$ & $\$ 119,533$ \\
$\mathbf{6}$ & $\$ 115,420$ & $\$ 113,238$ & $\$ 128,452$ & $\$ 131,692$ \\
$\mathbf{7}$ & $\$ 127,775$ & $\$ 127,785$ & $\$ 142,972$ & $\$ 150,876$ \\
$\mathbf{8}$ & $\$ 141,020$ & $\$ 137,412$ & $\$ 159,462$ & $\$ 175,493$ \\
$\mathbf{9}$ & $\$ 158,364$ & $\$ 146,579$ & $\$ 175,523$ & $\$ 195,287$ \\
$\mathbf{1 0}$ & $\$ 171,280$ & $\$ 158,289$ & $\$ 186,198$ & $\$ 215,132$ \\
$\mathbf{1 - 5}$ & $\$ 65,542$ & $\$ 71,712$ & $\$ 81,882$ & $\$ 80,997$ \\
$\mathbf{6 - 1 0}$ & $\$ 142,772$ & $\$ 136,661$ & $\$ 158,521$ & $\$ 173,696$ \\
\hline White & $\$ 107,858$ & $\$ 107,880$ & $\$ 126,255$ & $\$ 134,162$ \\
African American & $\$ 91,472$ & $\$ 91,693$ & $\$ 101,362$ & $\$ 110,150$ \\
Hispanic & $\$ 78,395$ & $\$ 78,464$ & $\$ 86,539$ & $\$ 96,100$ \\
\hline Male & $\$ 126,018$ & $\$ 120,532$ & $\$ 133,344$ & $\$ 140,019$ \\
Female & $\$ 84,308$ & $\$ 89,179$ & $\$ 107,660$ & $\$ 115,543$ \\
\hline All & $\$ 104,139$ & $\$ 104,154$ & $\$ 120,166$ & $\$ 127,313$ \\
No. of Observations & 5,579 & 3,078 & 3,368 & 4,780 \\
\hline \hline
\end{tabular}

Notes: Social Security wealth is estimated based only on earnings up to the date of cohort entry into HRS. Values are converted to 2010 USD using CPI. 


\section{Appendix Table III: Proportions Receiving SSDI}

\begin{tabular}{lllll}
\hline \hline & \multicolumn{3}{c}{ Year Cohort Ages 51-56 } \\
& $\mathbf{1 9 9 2}$ & $\mathbf{1 9 9 8}$ & $\mathbf{2 0 0 4}$ & $\mathbf{2 0 1 0}$ \\
\hline Decile of Lifetime Earnings & & & & \\
$\mathbf{1}$ & $3.1 \%$ & $4.9 \%$ & $10.1 \%$ & $8.0 \%$ \\
$\mathbf{2}$ & $3.9 \%$ & $6.5 \%$ & $10.8 \%$ & $13.4 \%$ \\
$\mathbf{3}$ & $7.2 \%$ & $7.4 \%$ & $7.3 \%$ & $16.8 \%$ \\
$\mathbf{4}$ & $5.1 \%$ & $7.7 \%$ & $9.3 \%$ & $15.4 \%$ \\
$\mathbf{5}$ & $4.9 \%$ & $8.0 \%$ & $9.4 \%$ & $7.6 \%$ \\
$\mathbf{6}$ & $4.9 \%$ & $4.8 \%$ & $5.3 \%$ & $8.3 \%$ \\
$\mathbf{7}$ & $3.0 \%$ & $3.1 \%$ & $2.4 \%$ & $3.3 \%$ \\
$\mathbf{8}$ & $2.3 \%$ & $2.4 \%$ & $2.1 \%$ & $0.6 \%$ \\
$\mathbf{9}$ & $1.2 \%$ & $0.6 \%$ & $1.4 \%$ & $2.1 \%$ \\
$\mathbf{1 0}$ & $0.3 \%$ & $0.0 \%$ & $0.5 \%$ & $0.8 \%$ \\
$\mathbf{1 - 5}$ & $4.8 \%$ & $6.9 \%$ & $9.4 \%$ & $12.2 \%$ \\
$\mathbf{6 - 1 0}$ & $2.3 \%$ & $2.2 \%$ & $2.3 \%$ & $3.0 \%$ \\
\hline White & & $3.9 \%$ & $5.3 \%$ & $6.5 \%$ \\
African American & $3.0 \%$ & $9.8 \%$ & $16.2 \%$ \\
\hline Hispanic & $7.6 \%$ & $9.0 \%$ & $6.7 \%$ & $6.3 \%$ \\
\hline All & $4.6 \%$ & $5.4 \%$ & $6.5 \%$ & $7.5 \%$ \\
\hline \hline & $4.5 \%$ & $5.2 \%$ & $5.2 \%$ & $7.7 \%$ \\
\hline & $2.8 \%$ & $3.9 \%$ & $5.9 \%$ & $7.6 \%$ \\
\hline & $3.6 \%$ & $4.6 \%$ & 3,368 & 4,780 \\
\hline & 3.078 & & \\
\hline
\end{tabular}

Notes: SSDI receipt is based on respondent self-report data summarized in the RAND user-friendly file, not on program information received from SSA 


\section{Appendix Table IV: Non-Retirement Wealth (2010 USD)}

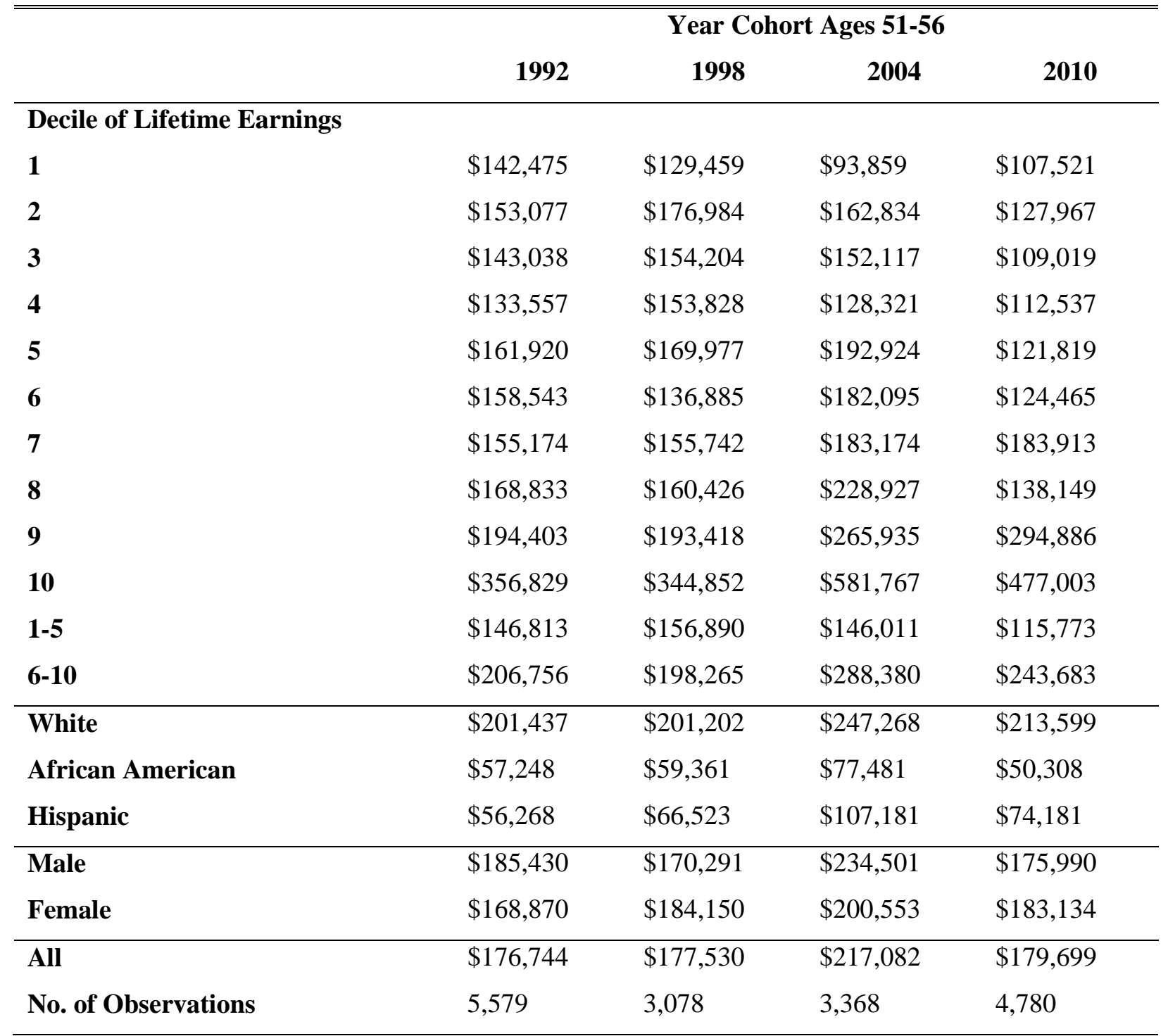

Notes: Non-retirement wealth is all household wealth, excluding IRAs, DC plans, and without augmentation for wealth value of annuity benefits received or scheduled. It is based on the RAND HxATOTB variable. For married and partnered couples, total household wealth was split evenly between partners. Values are converted to 2010 USD using CPI. 


\section{Appendix Table V: IRA Wealth (Individual, 2010 USD)}

\begin{tabular}{llllc}
\hline \hline & \multicolumn{4}{c}{ Year Cohort Ages 51-56 } \\
& $\mathbf{1 9 9 2}$ & $\mathbf{1 9 9 8}$ & $\mathbf{2 0 0 4}$ & $\mathbf{2 0 1 0}$ \\
\hline Decile of Lifetime Earnings & & & & \\
$\mathbf{1}$ & $\$ 3,501$ & $\$ 4,784$ & $\$ 6,968$ & $\$ 14,325$ \\
$\mathbf{2}$ & $\$ 5,539$ & $\$ 17,590$ & $\$ 12,634$ & $\$ 10,534$ \\
$\mathbf{3}$ & $\$ 5,115$ & $\$ 13,570$ & $\$ 22,425$ & $\$ 17,415$ \\
$\mathbf{4}$ & $\$ 7,964$ & $\$ 13,920$ & $\$ 12,810$ & $\$ 14,093$ \\
$\mathbf{5}$ & $\$ 9,738$ & $\$ 18,396$ & $\$ 23,317$ & $\$ 17,901$ \\
$\mathbf{6}$ & $\$ 12,775$ & $\$ 16,701$ & $\$ 28,767$ & $\$ 15,818$ \\
$\mathbf{7}$ & $\$ 11,648$ & $\$ 23,960$ & $\$ 24,376$ & $\$ 25,745$ \\
$\mathbf{8}$ & $\$ 18,318$ & $\$ 27,502$ & $\$ 25,628$ & $\$ 23,820$ \\
$\mathbf{9}$ & $\$ 21,612$ & $\$ 42,508$ & $\$ 43,673$ & $\$ 39,392$ \\
$\mathbf{1 0}$ & $\$ 55,351$ & $\$ 85,330$ & $\$ 103,621$ & $\$ 83,419$ \\
$\mathbf{1 - 5}$ & $\$ 6,371$ & $\$ 13,652$ & $\$ 15,631$ & $\$ 14,854$ \\
$\mathbf{6 - 1 0}$ & $\$ 23,941$ & $\$ 39,200$ & $\$ 45,213$ & $\$ 37,639$ \\
\hline White & $\$ 17,496$ & $\$ 30,580$ & $\$ 35,656$ & $\$ 31,187$ \\
African American & $\$ 3,968$ & $\$ 4,997$ & $\$ 7,338$ & $\$ 6,600$ \\
Hispanic & $\$ 3,415$ & $\$ 7,635$ & $\$ 9,688$ & $\$ 11,654$ \\
\hline Male & $\$ 20,507$ & $\$ 32,228$ & $\$ 36,243$ & $\$ 28,828$ \\
\hline Female & $\$ 10,289$ & $\$ 21,088$ & $\$ 24,846$ & $\$ 23,839$ \\
\hline \hline & $\$ 15,147$ & $\$ 26,409$ & $\$ 30,395$ & $\$ 26,238$ \\
\hline No. of Observations & 5,579 & 3,078 & 3,368 & 4,780 \\
\hline
\end{tabular}

Notes: IRA wealth is allocated between individuals based on the report of ownership given in HRS. Values are converted to 2010 USD using CPI. 


\section{Appendix Table VI: DB Pension Wealth (2010 USD)}

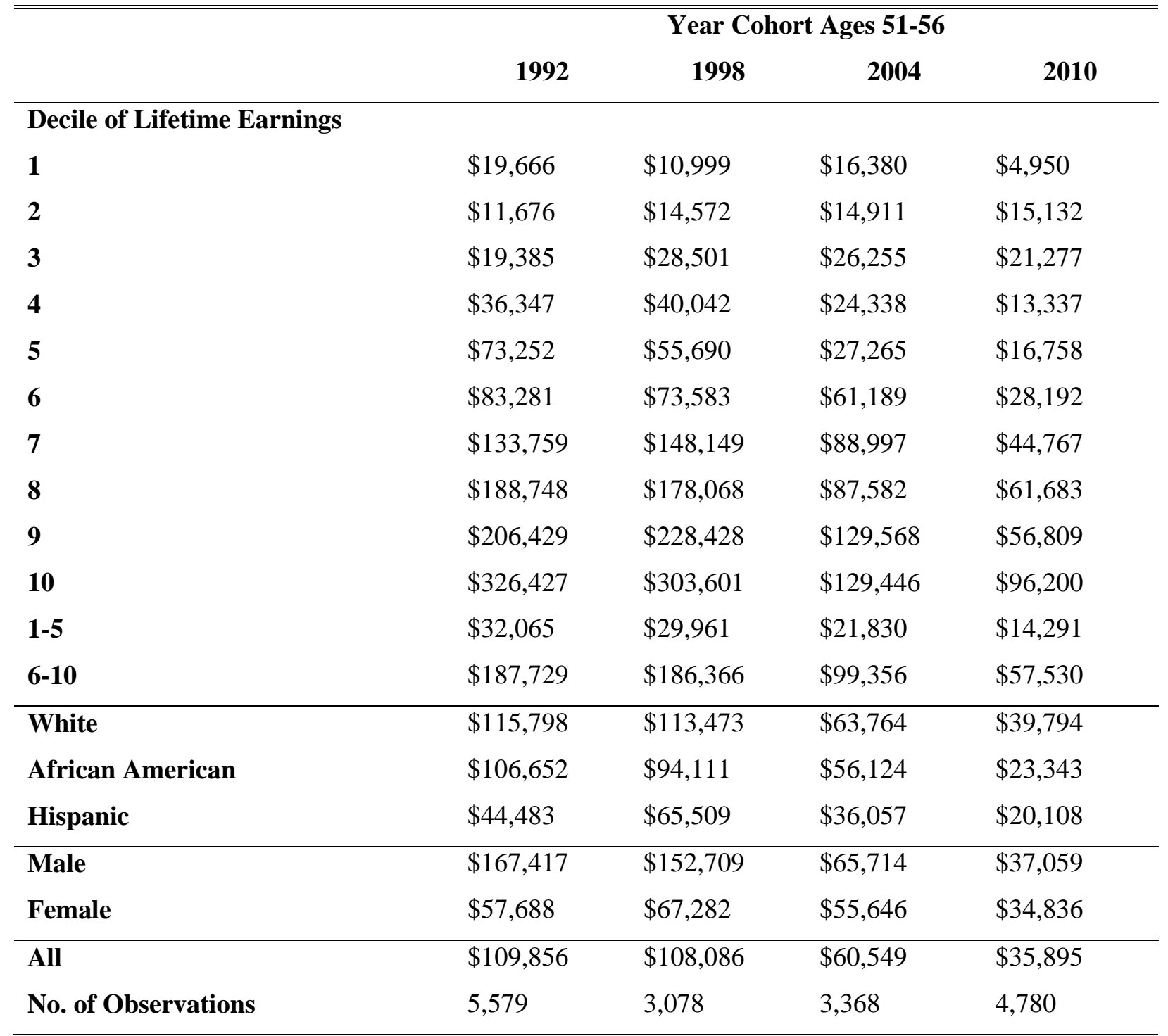

Notes: DB wealth on current jobs is estimated using methods described in text. It is the prorated value of $\mathrm{DB}$ wealth projected at future retirement ages. DB wealth on past jobs is taken from data underlying Gustman, Steinmeier, and Tabatabai (2010a). Values are converted to 2010 USD using CPI. 


\section{Appendix Table VII: DC Pension Wealth (2010 USD)}

\begin{tabular}{lllll}
\hline \hline & \multicolumn{4}{c}{ Year Cohort Ages 51-56 } \\
& $\mathbf{1 9 9 2}$ & $\mathbf{1 9 9 8}$ & $\mathbf{2 0 0 4}$ & $\mathbf{2 0 1 0}$ \\
\hline Decile of Lifetime Earnings & & & & \\
$\mathbf{1}$ & $\$ 3,327$ & $\$ 4,727$ & $\$ 4,862$ & $\$ 4,877$ \\
$\mathbf{2}$ & $\$ 2,192$ & $\$ 9,443$ & $\$ 7,208$ & $\$ 5,926$ \\
$\mathbf{3}$ & $\$ 3,715$ & $\$ 13,058$ & $\$ 7,410$ & $\$ 18,255$ \\
$\mathbf{4}$ & $\$ 4,134$ & $\$ 16,006$ & $\$ 19,903$ & $\$ 11,784$ \\
$\mathbf{5}$ & $\$ 8,205$ & $\$ 24,268$ & $\$ 16,044$ & $\$ 21,523$ \\
$\mathbf{6}$ & $\$ 9,319$ & $\$ 21,969$ & $\$ 24,548$ & $\$ 31,143$ \\
$\mathbf{7}$ & $\$ 15,439$ & $\$ 37,818$ & $\$ 42,733$ & $\$ 47,798$ \\
$\mathbf{8}$ & $\$ 26,068$ & $\$ 43,760$ & $\$ 44,423$ & $\$ 58,331$ \\
$\mathbf{9}$ & $\$ 42,048$ & $\$ 62,989$ & $\$ 60,612$ & $\$ 111,226$ \\
$\mathbf{1 0}$ & $\$ 107,273$ & $\$ 151,265$ & $\$ 129,681$ & $\$ 150,836$ \\
$\mathbf{1 - 5}$ & $\$ 4,315$ & $\$ 13,500$ & $\$ 11,085$ & $\$ 12,473$ \\
$\mathbf{6 - 1 0}$ & $\$ 40,029$ & $\$ 63,560$ & $\$ 60,399$ & $\$ 79,867$ \\
\hline White & $\$ 24,802$ & $\$ 42,861$ & $\$ 39,351$ & $\$ 54,351$ \\
African American & $\$ 8,816$ & $\$ 16,889$ & $\$ 27,220$ & $\$ 18,159$ \\
Hispanic & $\$ 9,948$ & $\$ 17,795$ & $\$ 12,237$ & $\$ 16,483$ \\
\hline Male & $\$ 37,668$ & $\$ 54,496$ & $\$ 48,941$ & $\$ 61,078$ \\
Female & $\$ 8,091$ & $\$ 23,869$ & $\$ 23,155$ & $\$ 32,322$ \\
\hline All & $\$ 22,152$ & $\$ 38,497$ & $\$ 35,711$ & $\$ 46,147$ \\
No. of Observations & 5,579 & 3,078 & 3,368 & 4,780 \\
\hline \hline
\end{tabular}

Notes: DC wealth is taken from self-report, with imputations for missing data. These estimates are not augmented by plans not reported by the respondent. Values are converted to 2010 USD using CPI. 


\section{Appendix Table VIII: Total Retirement Wealth (2010 USD)}

\begin{tabular}{llccc}
\hline \hline & \multicolumn{4}{c}{ Year Cohort Ages 51-56 } \\
& $\mathbf{1 9 9 2}$ & $\mathbf{1 9 9 8}$ & $\mathbf{2 0 0 4}$ & $\mathbf{2 0 1 0}$ \\
\hline Decile of Lifetime Earnings & & & & \\
$\mathbf{1}$ & $\$ 57,577$ & $\$ 54,692$ & $\$ 72,531$ & $\$ 56,908$ \\
$\mathbf{2}$ & $\$ 62,453$ & $\$ 97,249$ & $\$ 100,573$ & $\$ 99,427$ \\
$\mathbf{3}$ & $\$ 94,051$ & $\$ 129,819$ & $\$ 140,376$ & $\$ 142,665$ \\
$\mathbf{4}$ & $\$ 134,652$ & $\$ 161,273$ & $\$ 157,671$ & $\$ 138,357$ \\
$\mathbf{5}$ & $\$ 192,733$ & $\$ 201,093$ & $\$ 180,987$ & $\$ 175,715$ \\
$\mathbf{6}$ & $\$ 220,795$ & $\$ 225,491$ & $\$ 242,956$ & $\$ 206,846$ \\
$\mathbf{7}$ & $\$ 288,621$ & $\$ 337,712$ & $\$ 299,078$ & $\$ 269,185$ \\
$\mathbf{8}$ & $\$ 374,154$ & $\$ 386,742$ & $\$ 317,095$ & $\$ 319,327$ \\
$\mathbf{9}$ & $\$ 428,453$ & $\$ 480,504$ & $\$ 409,376$ & $\$ 402,714$ \\
$\mathbf{1 0}$ & $\$ 660,331$ & $\$ 698,485$ & $\$ 548,946$ & $\$ 545,587$ \\
$\mathbf{1 - 5}$ & $\$ 108,293$ & $\$ 128,825$ & $\$ 130,428$ & $\$ 122,614$ \\
$\mathbf{6 - 1 0}$ & $\$ 394,471$ & $\$ 425,787$ & $\$ 363,490$ & $\$ 348,732$ \\
\hline White & $\$ 265,954$ & $\$ 294,794$ & $\$ 265,026$ & $\$ 259,494$ \\
African American & $\$ 210,908$ & $\$ 207,690$ & $\$ 192,044$ & $\$ 158,252$ \\
Hispanic & $\$ 136,241$ & $\$ 169,403$ & $\$ 144,521$ & $\$ 144,346$ \\
\hline Male & $\$ 351,610$ & $\$ 359,965$ & $\$ 284,242$ & $\$ 266,985$ \\
Female & $\$ 160,376$ & $\$ 201,418$ & $\$ 211,307$ & $\$ 206,540$ \\
\hline All & $\$ 251,294$ & $\$ 277,146$ & $\$ 246,821$ & $\$ 235,593$ \\
No. of Observations & 5,579 & 3,078 & 3,368 & 4,780 \\
\hline \hline & 1545 & \\
\hline
\end{tabular}

Note: Total retirement wealth is the sum of IRA, DB, and DC wealth as reported in Appendix Tables 5, 6, and 7. Values are converted to 2010 USD using CPI. 


\section{Appendix Table IX: Total Retirement Wealth as Share of Lifetime Earnings}

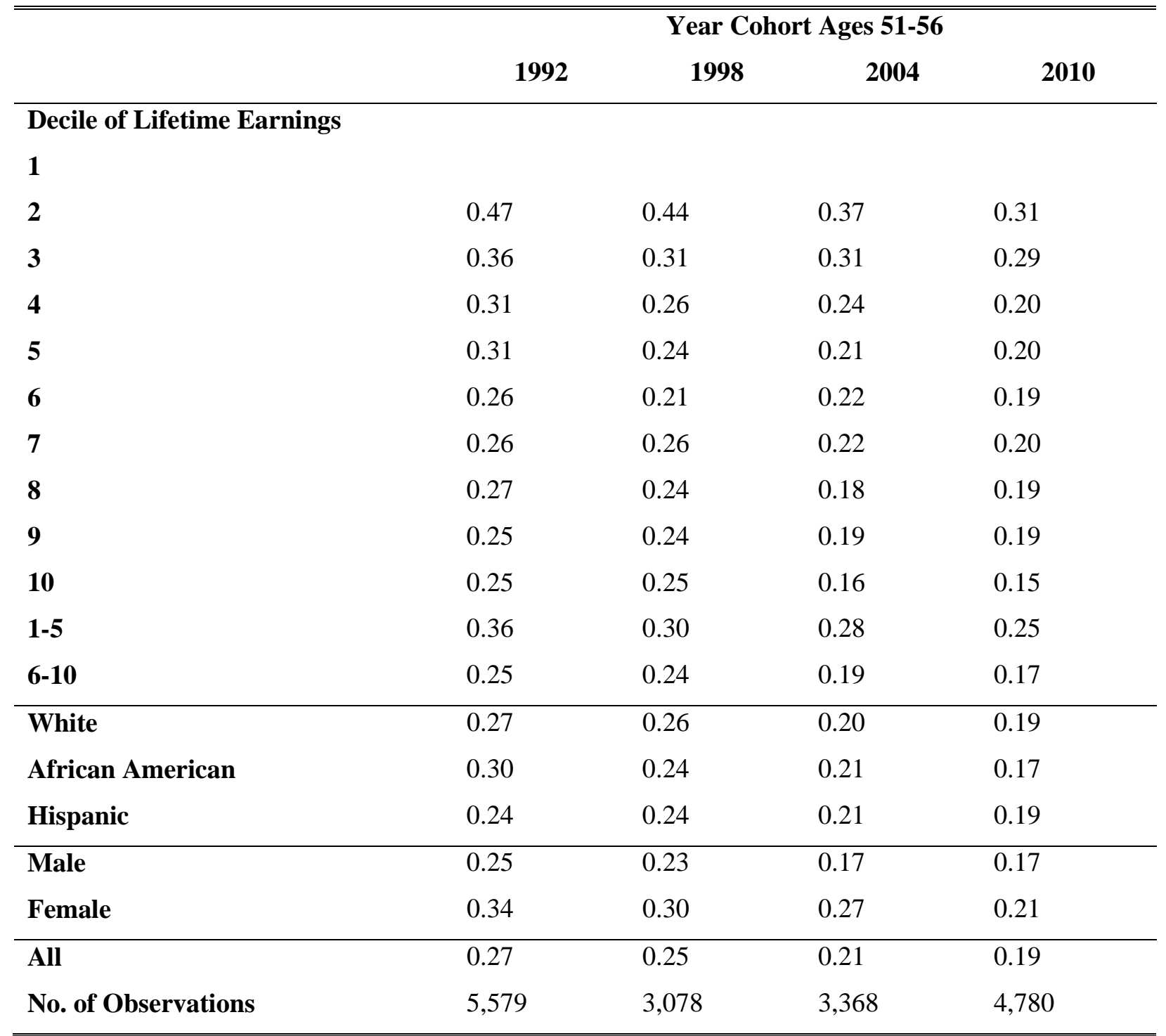

Notes: The ratio of retirement wealth to lifetime earnings is the ratio of Appendix Table VIII to Appendix Table I. 